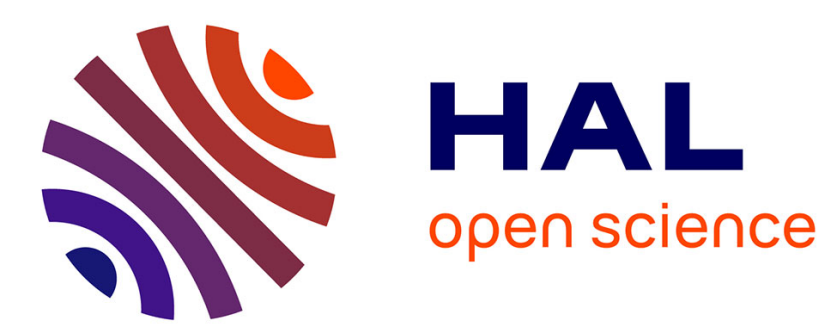

\title{
Mapping Medusae Fossae Formation materials in the southern highlands of Mars
}

\author{
S.K. Harrison, M.R. Balme, A. Hagermann, J.B. Murray, J-P. Muller
}

\section{To cite this version:}

S.K. Harrison, M.R. Balme, A. Hagermann, J.B. Murray, J-P. Muller. Mapping Medusae Fossae Formation materials in the southern highlands of Mars. Icarus, 2010, 209 (2), pp.405. 10.1016/j.icarus.2010.04.016 . hal-00676208

\section{HAL Id: hal-00676208 https://hal.science/hal-00676208}

Submitted on 4 Mar 2012

HAL is a multi-disciplinary open access archive for the deposit and dissemination of scientific research documents, whether they are published or not. The documents may come from teaching and research institutions in France or abroad, or from public or private research centers.
L'archive ouverte pluridisciplinaire HAL, est destinée au dépôt et à la diffusion de documents scientifiques de niveau recherche, publiés ou non, émanant des établissements d'enseignement et de recherche français ou étrangers, des laboratoires publics ou privés. 


\section{Accepted Manuscript}

Mapping Medusae Fossae Formation materials in the southern highlands of

Mars

S.K. Harrison, M.R. Balme, A. Hagermann, J.B. Murray, J-P. Muller

PII:

S0019-1035(10)00173-9

DOI:

10.1016/j.icarus.2010.04.016

Reference:

YICAR 9413

To appear in:

Icarus

Received Date: $\quad 18$ January 2010

Revised Date: $\quad 21$ April 2010

Accepted Date: $\quad 21$ April 2010

Please cite this article as: Harrison, S.K., Balme, M.R., Hagermann, A., Murray, J.B., Muller, J-P., Mapping Medusae Fossae Formation materials in the southern highlands of Mars, Icarus (2010), doi: 10.1016/j.icarus.2010.04.016

This is a PDF file of an unedited manuscript that has been accepted for publication. As a service to our customers we are providing this early version of the manuscript. The manuscript will undergo copyediting, typesetting, and review of the resulting proof before it is published in its final form. Please note that during the production process errors may be discovered which could affect the content, and all legal disclaimers that apply to the journal pertain. 
${ }^{1}$ Planetary and Space Science Research Institute, The Open University, Walton Hall, Milton Keynes, MK7 6AA, UK.

${ }^{2}$ Dept of Earth and Environmental Sciences, The Open University, Walton Hall, Milton 10 Keynes, MK7 6AA, UK.

*Corresponding author, $\underline{\text { s.k.harrison@ open.ac.uk }}$

${ }^{3}$ University College London, Department of Space \& Climate Physics, Mullard Space Science Laboratory, Holmbury St. Mary, Dorking, RH5 6NT, UK

18 Pages: 44

19 Tables: 2

20 Figures: 15 
21 Proposed Running Head: Mapping Medusae Fossae Formation outliers

23 Correspondence to:

24 Samantha K. Harrison

25 PSSRI

26 The Open University

27 Walton Hall

28 Milton Keynes

29 MK7 6AA

30 UK

31

32 Email: s.k.harrison@open.ac.uk

33

34

35

36

37

38

39

40

41

42

43

44

45

46

47 


\section{ABSTRACT}

49 The Medusae Fossae Formation (MFF) is an extensive deposit $\left(2.2 \times 10^{6} \mathrm{~km}^{2}\right.$, Bradley et

50 al., (2002)) of wind-eroded material of widely debated origin, which unconformably

51 overlies a considerable area of the crustal dichotomy boundary on Mars. The MFF shows

52 a variety of layering patterns, erosional styles and channel-like forms and has been

53 mapped into five main outcrops and three geological members according to exposure and

54 stratigraphy (Scott and Tanaka, 1986; 1987; Zimbelman et al., 1996). Away from the

55 three main lobes are numerous outliers of MFF materials. These have mainly been

56 reported in the northern lowlands regions (Watters et al., 2007b; Keszthelyi et al., 2008)

57 but few studies have examined the possibility of MFF outliers on high ground south of

58 the dichotomy boundary. We have searched Mars Orbiter Camera Narrow Angle (MOC

59 NA) images for outliers in this region. Our observations show that there are many MFF

60 outliers on the southern highlands. The characteristics of the outliers indicate materials

61 which overlie the underlying terrain for they appear widely in dips, craters and

62 topographic lows. The surfaces are typified by yardang fields and have a similar patchy

63 and discontinuous nature to materials of the upper member of the MFF. Most have

64 consistent lineation orientations across the wider area which match the dominant

65 orientation of yardangs in the main MFF outcrops. Furthermore, elevation data shows

66 that the maximum, minimum and mean elevations of these newly discovered outliers are

67 closest to those of the upper member of the MFF. We therefore conclude that these

68 deposits are MFF outliers and that they probably represent remnant upper member

69 material. We suggest that there might be two possible explanations for these outliers: 1)

70 the MFF had a much greater pre-erosional extent than previously estimated, or 2) 
71 Materials from the main outcrops were eroded and then blown south to accrue in the

72 highland areas, where they were subsequently reworked. We suggest that the topography

73 of the region favors the first option. We outline an "overflowing" layer-cake deposition

74 model, in which layers of sediment stacked up against the dichotomy boundary until they

75 reached the topographic level of the highlands. Further materials (that went on to become

76 upper-member MFF material and outliers) were then deposited across a wider area,

77 including south of the dichotomy boundary. Severe erosion subsequently removed much

78 of this material.

79

80 Keywords: Mars; Mars, Surface; Geological processes; 


\section{$81 \quad 1$ Introduction}

\section{$82 \quad 1.1$ The Medusae Fossae Formation}

83 The Medusae Fossae Formation (MFF) is an extensive but discontinuous

84 geological unit that can be found across approximately a quarter of the equatorial region

85 of Mars (130-240 E, 15 N-15 S; (Bradley et al., 2002)). Its E-W length, which extends

86 from the Amazonis Planitia area, to the southern Elysium Planitia is $\sim 5500 \mathrm{~km}$ (Tanaka,

87 2000). The deposit overlies the crustal dichotomy between the older Southern highlands

88 and the younger Northern lowlands, with a N-S extent of several $100 \mathrm{~km}$, reaching

89 locally up to $1000 \mathrm{~km}$ (Tanaka, 2000). The MFF comprises five primary outcrops or

90 lobes (Fig. 1), which themselves are mapped into three stratigraphic members: lower,

91 middle and upper, with an estimated total area of $2.2 \times 10^{6} \mathrm{~km}^{2}$ (Bradley et al., 2002). It

92 is possible that these lobes represent the degraded remnants of a once continuous deposit

93 (Bradley et al., 2002).

94 Fig. 1

95 Morphologically, the Medusae Fossae Formation materials are typified by a

96 discontinuous, highly eroded appearance (Fig. 2), and it is commonly agreed that they are

97 fine grained and friable in nature (Zimbelman et al., 1996; Zimbelman et al., 1997;

98 Tanaka, 2000; Bradley et al., 2002; Bridges et al., 2007; Mandt et al., 2007; Mandt et al.,

99 2008b; Carter et al., 2009; Kerber and Head, 2009). This long-standing interpretation is

100 rooted in the observed prevalent aeolian erosional features indicating modification of its

101 surface and by inference from thermal inertia measurements (Zimbelman et al., 2003). 
102 Current interpretations of its age, based upon relative stratigraphy (Scott and Tanaka,

103 1986; Tanaka et al., 1992; Zimbelman et al., 1999; Bradley et al., 2000; Tanaka, 2000;

104 Bradley et al., 2002; Shockey et al., 2004) and measurements of the size frequency

105 distribution of impact craters (Werner, 2005; Allen and Gregg, 2007; Hartmann, 2007;

106 Smith et al., 2008), places the MFF as a geologically young unit of Amazonian age. On

107 the other hand, it has been argued that local stratigraphic relationships (Kerber and Head, 108 2009) indicate deposition may have been sporadic over a much longer period and that

109 initial emplacement may have been as early as the Hesperian (Schultz and Lutz, 1988;

110 Head and Kreslavsky, 2001; Head and Kreslavsky, 2004; Schultz, 2007; Kerber et al., 111 2008; Kerber and Head, 2009).

\section{Fig. 2}

113 Importantly, the origins of the MFF remain uncertain, despite numerous studies

114 (including (Parker, 1991; Zimbelman et al., 1996; Zimbelman et al., 1997; Bradley et al.,

115 2002; Ivanov et al., 2003; Head and Kreslavsky, 2004; Shockey et al., 2004; McColley et

116 al., 2005; Shockey and Zimbelman, 2005; Bridges et al., 2007; Watters et al., 2007a;

117 Mandt et al., 2008a; Mandt et al., 2008b; Basilevsky et al., 2009; Carter et al., 2009;

118 Kerber and Head, 2009) that have constrained the age, distribution and material 119 properties. These studies have resulted in a variety of hypotheses for the formation 120 mechanism of the MFF, some of which are summarised in Table 1. Over time, some of

121 these hypotheses have been discounted based on newer evidence (see the review of

122 Mandt et al., 2008b). Recent radar data in particular suggest that the dielectric properties

123 of the MFF indicate the materials to be either dry, low density deposits (for example ash) 
124 or ice-rich deposits of some kind (Head, 2001; Nussbaumer, 2007; Watters et al., 2007a;

125 Carter et al., 2008; Kerber et al., 2008; Keszthelyi et al., 2008).

126 The most prominent surficial features of the MFF are tapered ridges called

127 yardangs, aeolian features carved in areas of easily erodible materials (Greeley and

128 Iverson, 1985, p134). Yardangs occur ubiquitously over the formation, often in large

129 clusters or fields, as is typical for these features on Earth (Greeley and Iverson, 1985,

130 p135). They have distinctive planform morphology, often described as an "inverted ships

131 hull" shape (Greeley and Iverson, 1985, p135). Some studies have also investigated the

132 progressional development of yardangs, linking them with other surface features

133 including mesas and troughs (Mandt et al., 2008a). The presence of yardangs and their

134 characteristics underpin much of the work herein, both because they are a readily

135 identifiable signature of the MFF surface type, and also because they are an indicator of

136 paleo wind direction.

$138 \quad \mathbf{1 . 2}$ Outlier occurrence of MFF materials

139 The MFF is extensively and intensively eroded and, in a number of large areas,

140 completely or partially stripped away. Such stripping can reveal features such as

141 exhumed craters and lavaflows (Zimbelman et al., 1996; Zimbelman et al., 1997). In

142 many cases, these underlying features appear to be minimally altered and well-preserved

143 (Sakimoto et al., 1999). This characteristic erosion is of great importance not only

144 because it results in surface features which are in many cases unique to this area of Mars 
145 but also because the erosional history of the formation is fundamental to understanding its

146 origins, particularly as it appears to postdate all other units in the region (Irwin et al., 147 2004).

148 Close study of the five main outcrops has found them to be stratigraphically and

149 topographically complex, although several studies have acknowledged that the mis-

150 location of member and formation boundaries has probably been an unavoidable by-

151 product of the combination of poor data quality and the varying levels of erosion across

152 the outcrops (Bradley et al., 2002; Sakimoto et al., 1999)). A qualitative study of erosion

153 rates for the formation has been made utilizing pedestal crater height measurements and

154 their distance from the main outcrops (Allen and Gregg, 2007). Results from this

155 suggested a non-liner rate of erosion. Studies of the paleo extent of the formation have

156 also been made, using gridded topography and assuming a single pre-existing mass of

157 MFF material, which estimated an area of $5 \times 10^{6} \mathrm{~km}^{2}$ prior to erosion (Bradley et al., 158 2002).

159 Over the surfaces between and around the main outcrops are numerous examples 160 of apparent outlying MFF materials. Outlying materials are defined in this case as 161 examples of surface morphology and erosional characteristics similar to those observed 162 on type examples of MFF materials within the main outcrops (Watters et al., 2007a; 163 Keszthelyi et al., 2008). These outliers may be clustered or isolated and the consistency 164 of their surfaces has been used to infer that the present-day discontinuous MFF outcrops 165 were once a laterally continuous stratigraphy (Hynek et al., 2003). Such outliers have 166 taken the form of eroded remnants (Hynek et al., 2003), extensions of the formation 
167 upslope (Sakimoto et al., 1999) and layers overlying the central peaks of nearby craters 168 (Zimbelman et al., 2003).

The majority of these previously observed outlier occurrences have been on the

170 northern lowlands above the dichotomy boundary and in the immediate vicinity of the

171 main outcrops. Few studies have examined such MFF outliers south of the dichotomy

172 boundary; however, some 300 m of MFF material was observed by (Bradley et al., 2000)

173 to be draped over the Labou Vallis channel terraces and to cover some of the channel

174 floor. Labou Vallis is a channel of about an average $900 \mathrm{~m}$ deep and $6 \mathrm{~km}$ wide

175 (widening to $18 \mathrm{~km}$ downstream), which lies just to the southeast of MFF lobe D in Fig.

176 1. The aim of our work is to explore the region further south to detect whether MFF

177 outliers exist on the topographically high, cratered highlands, whether there are sufficient

178 outliers to indicate that the MFF previously extended further south than its currently

179 agreed extent, and whether any such new data provides evidence on the origin of the 180 formation.

\section{2. Approach}

183 We have systematically searched Mars Orbiter Camera (MOC) Narrow Angle

184 (NA) images (Malin and colleagues, 1998)for evidence of the existence of materials of 185 similar morphology to that defined for the Medusae Fossae Formation. We have found 186 many examples of such materials and have analyzed their morphology, distribution and 187 azimuthal trends. Using these data, we sought to establish whether a consistent 
188 stratigraphy existed between these outliers and therefore whether the outliers do indeed

189 represent degraded MFF deposits. In addition to MOC NA data, we have also used Mars

190 Reconnaissance Orbiter Context Imager (CTX) images.

\section{$191 \quad 2.1$ Definition of Medusae Fossae Materials}

Key to the mapping process was establishing a defined set of morphologic criteria

193 for identifying MFF textures. Such definition needed to take into account the differing

194 levels of erosion over the five main outcrops and the different members exposed, each of

195 which has slightly different surface morphology. In this case, the definitions were derived

196 from close study of appropriate images and from the member definitions as given in

197 previous work (Head and Kreslavsky, 2001). The morphology of previously identified

198 outliers (Hynek et al., 2003; Sakimoto et al., 1999; Zimbelman et al., 2003) was also

199 taken into account. Figure 2 show examples of the range of morphologies seen across the

200 five main outcrops of the MFF.

201 Established examples of MFF material as observed in MOC NA images were 202 catalogued for each of the five outcrops. The MOC NA images were judged to be the best

203 resolution for the task (averaging roughly $3 \mathrm{~m} /$ pixel), based upon image assessment and

204 previous works. These were then used as the baseline for geomorphological definition of

205 the MFF materials being searched for. The surface descriptions of the three stratigraphic

206 divisions of the formation, as given by (Head and Kreslavsky, 2001), are summarised in

207 Table 2.

208 Table 2 
MFF materials of all three stratigraphic members commonly drape over the

210 underlying materials and are lightly cratered (Bradley and Sakimoto, 2001; Bradley et al.,

211 2002; Zimbelman et al., 1996). The principal surface feature of all members of the MFF

212 materials are yardangs and yardang fields. The majority of these yardangs trend in one of

213 two dominating directions (NW-SE or NE-SW), although they do also occur N-S and E-

214 W. The morphology of the yardangs can vary greatly in detail (Mandt et al., 2008b), but

215 they are distinctive enough to be easily identified.

216 Other notable MFF surface features include mesas (Mandt et al., 2008a; Mandt et

217 al., 2008b) and pits and pit chains (often interpreted as collapse features) (McColley et

218 al., 2005; Mandt et al., 2008a; Mandt et al., 2008b; Mandt et al., 2009).

219 Ultimately, the morphologic criteria for identification were summarized as:

220 1. discontinuous nature

2212 2. the presence of yardangs, either individually or in fields; unidirectional and

$222 \quad$ bidirectional

223 3. other erosional and aeolian modification features

224 4. the presence of ripple and ridge features; unidirectional and bidirectional

225 5. pits and pit chains, often progressing into mesa formation. 


\subsection{Initial transect survey}

A preliminary survey was performed to quickly search for possible MFF outliers

231 across the widest longitude range possible. Five transect lines were constructed which

232 passed through one of the five main MFF lobes and extended into the region southward

233 of the formation. These transects were overlain on a map of the image footprints using a

234 GIS (Geographical Information System). By studying any image within $50 \mathrm{~km}$ of these

235 transects, a relatively small number of images could be quickly assessed to establish any

236 potential occurrences of outliers. This also provided a cross section of images from

237 within each of the established MFF lobes enabling us to create a bank of comparison

238 images of MFF morphology. Each transect started a short distance north (between 100

239 and $200 \mathrm{~km}$ ) of the main MFF lobe and then continued a longer distance south (between

$240750 \mathrm{~km}$ and $1000 \mathrm{~km}$ depending on the transect position) (Fig. 3).

$241 \quad$ Fig. 3

Each selected image was examined and the presence of MFF material recorded.

243 Given the nature of the transect lines, almost all of the positive identifications were, as

244 expected, recorded within the five main outcrops themselves, and in the immediate

245 surroundings areas on the lowlands. The vast majority of images with no trace of MFF

246 material were distributed across the southern highland regions. However, some apparent

247 outlying MFF materials were found in one area of the southern highlands: the southern

248 region of Transect 5 in the vicinity of the Mangala Valles region. For this reason, we

249 initiated a more in-depth study of all the images in this region. 
251 We defined a large study area that covered part of transect 4 and 5 (Fig. 4). Each

252 of the $>350$ MOC NA images that fell within this region was selected, downloaded and

253 processed using US Geological Survey "ISIS" software prior to being loaded into a GIS.

254 These images were examined individually, a record kept of any possible MFF materials

255 and these data converted into a shape-file within the GIS. Where possible, the direction of

256 inferred yardang-forming winds was also recorded as described in more detail in section

2573.3 below.

$258 \quad$ Fig. 4

259 We also utilized new CTX images in the defined study area. These were also

260 processed in ISIS and ingested into the GIS. CTX images have generally poorer spatial

261 resolution than MOC NA (6m/pixel as opposed to up to $1 \mathrm{~m} /$ pixel) but each image covers

262 an area 1-2 orders of magnitude larger than MOC NA. Additionally, although MOC NA

263 coverage is well-distributed but covers only a low percentage of continuous area, the

264 CTX coverage is patchy but provides a larger total coverage (Fig. 5). In some areas the

265 CTX coverage is almost continuous. We analyzed the morphology, extents and

266 directionality trends of MFF outliers in CTX images in the same way as we did using

267 MOC NA data.

268 Fig. 5 


\section{3. Results}

\section{$273 \quad 3.1$ General observations}

The new southern outliers observed in the images are characterized by extreme

275 degradation. They most commonly occur in dips and troughs and on channel and crater

276 floors, and often become visibly more eroded, or in fact missing completely, across

277 nearby areas (Fig. 6). Additionally, they occur across eroded older craters, particularly on

278 the raised edges (Fig. 7). Occasionally, the MFF-like materials terminate at scarp edges,

279 such as crater interior slopes, but then continue at the base of the slope.

$280 \quad$ Fig. 6

$281 \quad$ Fig. 7

The texture is typified by pronounced ridges, interpreted as fields of yardang

283 features, overlying smoother material in most cases. However, there are examples where

284 traces of MFF materials overlie rough textures.

Although the dominant directional trend, defined by the general orientation of the

286 yardang features, was observed to be diagonally NW-SE or SE-NW, there were other

287 orientations observed, including NNW-SSE, NNE-SSW and N-S. There were also a 288 number of examples where bi-directionality or multi-directionality occurred, in some of 289 these cases resulting in a crosshatch appearance (Fig. 8). Detailed observation of yardang 290 morphology was used to establish specific wind direction as described in section 3.3.

$291 \quad$ Fig. 8 
293 is similar to examples of MFF upper member materials that occur primarily toward the

294 southern edges of lobes D and E where they are observed in > 20 MOC NA images. Both

295 these materials (Fig. 9a) and the outliers (Fig. 9b) exhibit an extremely degraded

296 appearance, are preferentially concentrated in local topographic lows and contain small

297 (c. 30m width) and very tightly packed yardang features, sometimes with poorly defined

298 crosshatching. In general, though, the outlier morphologies do not completely match any

299 of the previously described MFF member materials, but have enough similar features for

300 us to be confident that we are dealing with the same formation. The implications of the

301 similarity of some outliers to some Lobe D and E upper member terrains are further

302 discussed in section 4.

303 Fig. 9

\subsection{Distribution}

The distribution of outlying deposits is both patchy and discontinuous, as far as

307 can be judged from the sparse and non-uniform image coverage. We found examples of

308 both isolated outliers and of clusters of near-continuous MFF-material. Many of the

309 larger outlier extents are in close proximity to smaller outliers and show a clear 310 relationship to each other.

311 Pitted patches, wherein the materials have numerous teardrop-shaped pits across 312 them, resembling negative form yardangs (also seen on the main outcrops) appeared 
313 frequently. These materials then grade into the more typical raised texture at the eroded

314 edges of these patches. .Isolated and lightly-clustered yardangs are often found at the

315 edges of individual outliers, becoming less intensely clustered the further from the outlier

316 concerned.

Overall, the outliers were most commonly found to the south of, and straddling,

318 the crustal dichotomy, positionally between the bases of the two easternmost MFF

319 outcrops (Fig. 10). It is also here that the largest continuous area was mapped, over a

320 significant section west of the downstream Mangala Valles. Occurrences in channel

321 floors were also common. To the west, many outliers, some of continuous extent, were

322 observed in the highland region south of lobe D, particularly across and within craters.

323 Another notable continuous example is that which lies in the furthest east corner of the

324 study area, on a relatively high but smooth region, south of lobe E. Further south within

325 the study area, the outliers become more sparse and eroded, often comprising only trace

326 extents. For example, several small outliers occurred on the relatively flat area bounded

327 to the west by Mangala Valles and to the east by a large range of hills; this area is shown

328 close up in Fig. 11.

$329 \quad$ Fig. 10

$330 \quad$ Fig. 11

\section{$331 \quad 3.3$ Orientation}

We found that the meter-scale resolutions of both MOC NA and CTX images

333 were insufficient for more detailed analysis of the morphologies of the MFF erosional 
334 features. For example, ascertaining the exact orientation of the yardangs, and thus the

335 wind direction, was difficult. We therefore used 25cm/pixel High Resolution Imaging

336 Science Experiment (HiRISE) data (McEwen and colleagues, 2007) to derive wind

337 direction from yardang morphology. Figure 12, showing a yardang in HiRISE image

338 PSP_007973_1750, provides an example of how morphology was used to infer wind

339 direction. Although the morphology is sometimes ambiguous and the HiRISE coverage

340 somewhat sparse, we measured yardang orientations for 21 examples in the newly

341 discovered southern outliers. The inferred wind directions are shown in Fig. 13. The

342 dominant wind directions were found to be SW and NE, which mirrors those which were

343 inferred from visual assessment of the main MFF lobes D and E. We suggest that this

344 match between inferred wind directions reinforces the interpretation that the outliers we

345 have mapped are MFF material, and thus were deposited and reworked under similar

346 climate conditions as that of the main MFF lobes. The simplest explanation is that these

347 outliers are the remnants of a previously larger MFF that extended much further south

348 than previously thought.

$349 \quad$ Fig. 12

$350 \quad$ Fig. 13

351

$352 \quad 3.4$ Stratigraphy

353 The Medusae Fossae Formation, by definition, consists of several different

354 stratigraphic units (Scott and Tanaka, 1986) and the central lobe (C) is the only one on

355 which all three of these units can be indentified. The division into the three members is

356 extremely important in regard to relating the stratigraphy of the outliers to that of the 
357 main lobes. The style of deposition of each member is uncertain. For example, it has not

358 been demonstrated that deposition occurred sequentially in a "layer cake" scenario (nor if

359 such a scenario included periods of erosion resulting in unconformities) or instead if the

360 depositional processes were spatially and temporally heterogeneous. Furthermore, the

361 crosshatching appearance resulting from bidirectionality in the yardangs could indicate

362 differing stratigraphic layers within the materials themselves (Kerber and Head, 2009).

363 We suggest that two possibilities exist: 1) that the new outliers are representative of one

364 specific member of the Medusae Fossae Formation, or 2) that their morphology

365 represents the highly degraded form of any of the MFF members.

366 To test these hypotheses, polygonal shapefiles were created in a GIS that

367 represented the extents of the MFF outliers discovered in both the MOC NA and CTX

368 images. These data can be seen in Fig. 10. Further shapefiles were created to represent

369 the extent of each individual lobe, as well as the extents of the individual members within

370 them. Elevation statistics were then computed using these shapefiles to delineate the areas

371 in which the topographical data were analyzed. We used the gridded 128 pixel per degree

372 Mars Orbiter Laser Altimeter (MOLA) topography data (Smith and colleagues, 1998).

373 The elevation data, summarized in Fig. 14, show that the maximum, minimum

374 and mean elevations of the newly discovered outliers are closest to those of the upper

375 member of the MFF. This is not surprising given that we are searching an area of higher

376 and more variable altitude, but as discussed in section 3.1, the outliers share morphologic

377 characteristics with a subset of the upper member materials. Together with the elevation 
378 trends, this might suggest that the outliers are more likely to be remnants of the upper

379 member than the middle or lower members.

380 Fig. 14

381

382 4. Discussion

The morphology and patchy, discontinuous nature of the newly identified outlier

384 materials are very similar to MFF outliers found around areas of the upper member on

385 lobes $\mathrm{D}$ and $\mathrm{E}$. The characteristics of the outliers are indicative of materials which

386 initially draped the underlying terrain since they appear widely in dips, craters and

387 topographic lows.

388 The extent shapefiles (Fig. 10) illustrate the widespread aspect of the outlier

389 spatial extents. They are most common in the north of the study region, with relatively

390 smaller extents in the more southern areas - often only tiny outcrops. If the outliers

391 represent the remnants of a once continuous layer, the Medusae Fossae Formation might

392 once have extended up to $870 \mathrm{~km}$ south of the crustal dichotomy boundary (Fig. 15), and

393 these areas have since been very heavily eroded.

394 Fig. 15

The elevation statistics (Fig. 14) show that the elevation trends for the outlier

396 materials around Mangala Valles are most similar to those of the upper member of the

397 MFF. This could represent skewing due to the underlying topography, given that the 
398 outliers rest upon the southern highlands, but these results may suggest that the outliers

399 are representative of upper member MFF materials. The similarity in morphology

400 between certain areas of the upper member and some of the outliers further supports this

401 possibility.

However, the outliers are not always morphologically similar to the upper

403 member materials. Therefore, we suggest that either a) both the outliers and the

404 morphologically similar upper member materials are examples of eroded areas of upper

405 member deposits, or b) both are examples of aeolian materials eroded from elsewhere on

406 the MFF and subsequently reworked. The first option is somewhat supported by

407 observations of spatially related morphologies on the upper members and the outliers,

408 which could be taken to represent a slightly earlier progressional stage in the erosion:

409 some tightly packed yardang features possess morphologic characteristics that indicate a

410 history of less severe erosion than in the outliers. While we cannot discount the second

411 option, we suggest that aeolian materials on Mars more commonly collect in topographic

412 lows than remain deposited on topographic highs, and therefore suggest that this is less

413 likely than the first option.

414 If the mapped outliers do represent upper member materials, we then can combine

415 a simple layer cake stratigraphic model, in which it is assumed that each member of the

416 MFF was deposited sequentially, with the "sediment trap" hypothesis of Irwin et al

417 (2004) where the crustal dichotomy acted to trap sedimentary materials. Here we propose

418 a scenario in which deposition occurred on the highlands following deposition in the

419 lowlands to the north. In this hypothesis, the deposits sequentially stacked up against the 
420 boundary, eventually reaching the height of the southern highlands. The latter stage upper

421 member deposits then ceased to be confined by the topographic boundary, "overflowed"

422 it and were deposited across the nearby highlands. The topography seen today shows

423 evidence the products of severe erosion of this "overflowed" layer-cake deposition style.

424 The layer cake model for the MFF may be oversimplified as it does not take into account

425 observed complexities of the member stratigraphies (Sakimoto et al., 1999; Bradley et al., 426 2002; Kerber and Head, 2009).

We can use our new estimate of the paleo extent of the MFF in this region to 428 derive the volume of additional material here before erosion. To do this, we have 429 assumed that the greatest former extent of the MFF in this region was as shown in Fig.

43016 , and that its uppermost surface was at the same height as the majority of the outliers

431 we have found on the southern highlands. This is clearly an over-simplification, but there 432 seems little alternative. Using the GIS, we have estimated a maximum removed 433 paleovolume of $5.7 \times 10^{6} \mathrm{~km}^{3}$ for a region including Lobes D and E and the outliers we 434 have presented here (Fig. 16). This assumes a very basic uniform layer-cake structure 435 with vertical sides. Calculations of the volumes of the two easternmost MFF lobes, using 436 a basal elevation of -3300 , suggest current volumes of $6.6 \times 10^{5}$ and $8.9 \times 10^{5} \mathrm{~km}^{3}$ for 437 lobes $\mathrm{D}$ and $\mathrm{E}$ respectively. The lobe volumes are also notably higher than would be 438 suggested by the total current volume for the formation of $1.4 \times 10^{6} \mathrm{~km}^{3}$ as calculated by 439 Bradley et al. (2002), who used similar basal elevation. The same authors estimated a 440 paleo-area for the entire formation at $5 \times 10^{6} \mathrm{~km}^{2}$, compared to our total calculations of $4412.14 \times 10^{6} \mathrm{~km}^{2}$ for the area shown in Fig. 16 alone. 
Our results show that the MFF paleovolume is about three times higher than that

443 seen today. The volume of removed material is particularly interesting when compared to

444 Hayward et al.'s (2007) estimate of only $3600 \mathrm{~km}^{3}$ for the global dune field volume on

445 Mars, as it raises the question of where all this material has gone. The answer to this

446 question is not immediately obvious, but it is possible the removed material can be found

447 in the form of surface regolith, crater infill or perhaps even buried sediments in the

448 northern plains.

449 Our results support the hypothesis that the Medusae Fossae Formation was once

450 present over a much larger area than is currently visible and suggest that the MFF

451 contained an even larger volume of material than previously thought (e.g. Bradley et al., 452 2002).

The hypothesis that the highland outliers are progressively more eroded and more

454 widely spaced towards the south of the study area could indicate either that the southern 455 areas underwent more extreme erosion than the northern areas or that the deposition 456 thickness decreased to the south. This latter interpretation could fit with both the 457 "overflow" hypothesis presented above and the hypothesis of southern reworked deposits, 458 particularly if they were preferentially laid down close to the boundary due to wind

459 conditions. Overall, this would mean that either only the upper member of the Medusae 460 Fossae Formation extended a significant distance south or that the MFF itself did not 461 originally extend south but that the products of its erosion did. 
Based upon the work done to date, and led by the definitions given in Section 3.1,

465 we infer that eroded materials observed over the Mangala Valles region are examples of

466 outlying Medusae Fossae Formation materials. Trends in yardang direction on both the

467 MFF and the outliers tend to support this conclusion.

The topographic distribution of the outliers is most similar to the upper member of

469 the MFF. Morphologically, there is similarity between some outliers and some upper 470 member terrains in lobes D and E.

471 We suggest that there are two possible explanations for the presence of these outliers:

1. The MFF had a much larger pre-erosional extent than previously thought.

2. These materials were initially eroded from the main northern MFF, transported southward by wind, deposited onto the highlands and then subsequently reworked.

476 At the moment, we suggest that the first option is the more likely one, which corresponds

477 also with results from recent mapping work by Zimbelman (2010) in the western

478 Medusae Fossae. We present an "overflowing” layer-cake model for deposition in which

479 approximately horizontal stacks of sediment built up north of, and against, the dichotomy

480 boundary until they attained the topographic level of the highlands. Subsequent materials

481 (that went on to become upper-member MFF material and outliers) were then deposited

482 across a wide area, including well south of the dichotomy. Severe erosion then removed

483 much of the deposited material. We also present some basic paleo-area and paleovolume 
484

485

486

487

488

489

490

491

492

494

495

496

497

498

499

500

501

502

503

504

505

506

507

508

509

510

511

512

513

514

515

516

estimations that imply that the Medusae Fossae Formation once covered an area much larger than any previous estimates.

We conclude that the MFF was probably emplaced by airfall and windblown deposition of fine sediments. Deposition as episodic ignimbrites, fine grade aeolian materials (Zimbelman et al., 2003; Mandt et al., 2007) or as ice-rich deposits laid down during periods of high obliquity (Head, 2001; Head and Kreslavsky, 2001; Head and Kreslavsky, 2004; Nussbaumer, 2007) therefore seem the most likely models for formation.

\section{References}

Allen, J. G., Gregg, T. K. P., 2007. Using pedestal craters around the Medusae Fossae Formation, Mars, to constrain erosion rates Lunar and Planetary Science XXXVIII Abstract \#2016.

Basilevsky, A. T., Neukum, G., Kneiss1, T., Dumke, A., 2009. Geologic analysis of HRSC images of the area east of the Mangala Valles head graben. Lunar and Planetary Science XL Abstract \#1833.

Bradley, B. A., Grosfils, E. B., Sakimoto, S. E. H., 2000. Boundaries and stratigraphy of the Medusa Fossae Formation and Elysium Basin materials using Mars Orbiter Laser Altimeter (MOLA) data. Lunar and Planetary Science XXXI Abstract \#2055.

Bradley, B. A., Sakimoto, S. E. H., Frey, H., Zimbelman, J. R., 2002. Medusae Fossae Formation: New perspectives from Mars Global Surveyor. Journal of Geophysical Research. 107, 5058.

Bridges, N. T., Geissler, P. E., McEwen, A. S., Thomson, B. J., Chuang, F. C., Herkenhoff, K. E., Keszthelyi, L. P., Martinez-Alonso, S., 2007. Windy Mars: A dynamic planet as seen by the HiRISE camera. Geophysical Research Letters. 34.

Carter, L. M., Campbell, B. A., Watters, T. R., Seu, R., Phillips, R. J., Biccari, D., Holt, J. W., Leuschen, C. J., Plaut, J. J., Safaeinili, A., Orosei, R., Smrekar, S. E., Putzig, N. E., Egan, A. F., Bernardini, F., Team, t. S., 2008. SHARAD sounding RADAR observations of the Medusae Fossae Formation, Mars Lunar and Planetary Science XXXIX Abstract \\#1721.

Carter, L. M., Campbell, B. A., Watters, T. R., Phillips, R. J., Puzig, N. E., Safaenili, A., Plaut, J. J., Okubo, C. H., Egan, A. F., Seu, R., Biccari, D., Orosei, R., 2009. 
Shallow radar (SHARAD) sounding observations of the Medusae Fossae Formation. Icarus 199, 295-302.

Greeley, R., Iverson, J. D., 1985. Wind as a geological process on Earth, Mars, Venus and Titan. Cambridge University Press, Cambridge.

Greeley, R., Guest, J. E., Geologic map of the eastern equatorial region of Mars, Map I1802-B. 1987.

Hartmann, W. K., 2007. Support for Crater Count Chronometry and Evidence for Obliquity-driven Ice Deposition on Mars. Bulletin of the American Astronomical Society. 39, 436.

Hayward, R. K., Mullins, K. F., Fenton, L. K., Hare, T. M., Titus, T. N., Bourke, M. C., Coleprete, A., Christensen, P. R., 2007. Mars Global Digital Dune Database and initial science results. Journal of Geophysical Research. 112.

Head, J. W., 2001. Medusae Fossae Formation as ancient polar deposits?: Tests and new data on straigraphic relationships. Lunar and Planetary Science XXXII Abstract $\# 1394$.

Head, J. W., Kreslavsky, M. A., 2001. Medusae Fossae Formation as volatile-rich sediments deposited during high obliquity: An hypothesis and tests Conference on the Geophysical Detection of Subsurface Water on Mars Abstract \#7053.

Head, J. W., Kreslavsky, M. A., 2004. Medusae Fossae Formation: Ice-rich airborne dust deposited during periods of high obliquity? . Lunar and Planetary Science XXXV Abstract \#1635.

Hynek, B. M., Phillips, R. J., Arvidson, R. E., 2003. Explosive volcanism in the Tharsis region: Global evidence in the Martian geologic record. Journal of Geophysical Research. 108, 5111.

Irwin, R. P., Watters, T. R., Howard, A. D., Zimbleman, J. R., 2004. Sedimentary resurfacing and fretted terrain development along the crustal dichotomy boundary, Aeolis Mensae, Mars. Journal of Geophysical Research. 109.

Ivanov, M. A., Litvak, M. L., Mitrofanov, I. G., Boynton, W., Saunders, R. S., 2003. Medusae Fossae-Elysium region, Mars: Depression in the HEND/ODYSSEY maps of Mars epithermal neutrons Lunar and Planetary Science XXXIV Abstract $\# 1105$.

Kerber, L., Head, J. W., Madeleine, J. B., Wilson, L., Forget, F., 2008. Modelling ash dispersal from Apollinaris Patera: Implications for the Medusae Fossae Formation Lunar and Planetary Science XXXIX Abstract \#1881.

Kerber, L., Head, J. W., 2009. The Age of the Medusae Fossae Formation: Evidence of Hesperian Emplacement from Crater Morphology, Stratigraphy, and Ancient Lava Contacts. Icarus. 206, 669-684.

Keszthelyi, L., Jaeger, W. L., team, t. H., 2008. HiRISE observations of the Medusae Fossae Formation Lunar and Planetary Science XXXIX Abstract \#2420.

Malin, M. C., colleagues, 1998. Early views of the martian surface from the Mars Orbiter Camera of Mars Global Surveyor. Science. 279, 1681-1685.

Mandt, K. E., de Silva, S., Zimbelman, J. R., Crown, D. A., 2007. A synoptic approach to evaluating the origin of the Medusae Fossae Formation, Mars Lunar and Planetary Science XXXVIII Abstract \#1823. 
Mandt, K. E., de Silva, S., Zimbelman, J. R., 2008a. Erosional progressions in the Medusae Fossae Formation, Mars Lunar and Planetary Science XXXIX Abstract \#2086.

Mandt, K. E., de Silva, S. L., Zimbleman, J. R., Crown, D. A., 2008b. Origin of the Medusae Fossae Formation, Mars: Insights from a synoptic approach. Journal of Geophysical Research. 113, E12011.

Mandt, K. E., De Silva, S., Zimbelman, J. R., Wyrick, D., 2009. Distinct erosional progressions in the Medusae Fossae Formation, Mars, indicate contrasting environmental conditions. Icarus. 204, 471-477.

McColley, S. M., Head, J. W., Neukum, G., Team, t. H., 2005. The Medusae Fossae Formation: Geological characteristics and topographic and stratigraphic relationships of the lower member along southeastern Elysium Planitia Lunar and Planetary Science XXXVI Abstract \#1184.

McEwen, A. S., colleagues, 2007. Mars Reconnaissance Orbiter's High Resolution Imaging Science Experiment (HiRISE). Journal of Geophysical Research. 112.

Nussbaumer, J., 2007. Analysis of the Elysium Region, Mars Lunar and Planetary Science XXXVIII Abstract \#1217.

Parker, T. J., 1991. A comparison of the Martian Medusa Fossae Formation with terrestrial carbonate platforms. Lunar and Planetary Science XXII 1029-1030.

Sakimoto, S. E. H., Frey, H. V., Garvin, J. B., Roark, J. H., 1999. Topography, roughness, layering and slope properties of the Medusa Fossae Formation from Mars Orbiter Laser Altimeter (MOLA) and Mars Orbiter Camera (MOC) data. Journal of Geophysical Research. 104, 24,141 - 22,154.

Schultz, P. H., Lutz, A. B., 1988. Polar wandering on Mars. Icarus. 73.

Schultz, P. H., 2007. Planetary science: Hidden Mars. Science. 318, 1080-1081.

Scott, D. H., Tanaka, K. L., USGS Map I-1802-A. 1986.

Shockey, K. M., Zimbelman, J. R., Friedmann, S. J., Irwin, R. P., 2004. Geologic mapping of the Medusae Fossae Formation on Mars. Lunar and Planetary Science XXXV Abstract \#1539.

Shockey, K. M., Zimbelman, J. R., 2005. The Medusae Fossae Formation: Mapping the origins Lunar and Planetary Science XXXVI Abstract \#1799.

Smith, D. E., colleagues, 1998. Topography of the northern hemisphere of Mars from the Mars Orbiter Laser Altimeter. Science. 279, 1686-1692.

Smith, M. R., Gillespie, A. R., Montgomery, D. R., 2008. Effect of obliteration on cratercount chronologies for Martian surfaces. Geophysical Research Letters. 35.

Tanaka, K. L., Scott, D. H., Greeley, R., Global Stratigraphy. In: H. H. Kieffer, et al., Eds.), Mars. The University of Arizona Press, Tucson, Arizona, 1992, pp. 345382.

Tanaka, K. L., 2000. Dust and ice deposition in the Martian geologic record. Icarus. 144, 254-266

Watters, T. R., Campbell, B., Carter, L., Leuschen, C. J., Plaut, J. J., Picardi, G., Orosei, R., Safaeinili, A., Clifford, S. M., Farrell, W. M., Ivanov, A. B., Phillips, R. J., Stofan, E. R., 2007a. Radar Sounding of the Medusae Fossae Formation Mars: Equatorial Ice or Dry, Low-Density Deposits? Science 318, 1125-1128.

Watters, T. R., McGovern, P. J., Irwin, R. P., 2007b. Hemispheres apart: The crustal dichotomy on Mars. Annual Review of Earth and Planetary Science 35, 621-52. 
607

608

609

610

611

612

613

614

615

616

617

618

619

620

621

622

623

624

625

626

627

628

629

630

631

632

Werner, S. C., Major Aspects of the Chronostratigraphy and Geologic Evolutionary History of Mars (Unpublished PhD Thesis). Fachbereich Geowissenschaften Freie Universität Berlin, 2005.

Zimbelman, J. R., Crown, D., Jenson, D., 1996. Initial investigation of the enigmatic massive deposits in Amazonis Planitia, Mars. Lunar and Planetary Science XXVII Abstract \#1748.

Zimbelman, J. R., Crown, D. A., Grant, J. A., Hooper, D. M., 1997. The Medusae Fossae Formation, Amazonis Planitia, Mars: Evaluation of proposed hypotheses of origin. Lunar and Planetary Science XXVIII Abstract \#1482.

Zimbelman, J. R., Hooper, D., Crown, D., Grant, J., Sakimoto, S. E. H., Frey, H., 1999. Medusae Fossae Formation, Mars: An assessment of possible origins utilising early results from Mars Global Surveyor. Lunar and Planetary Science XXX Abstract \#1652.

Zimbelman, J. R., Bender, K. C., Harris, J. C., 2003. Geologic mapping applications using THEMIS data for the Medusae Fossae Formation, Mars. Lunar and Planetary Science XXXIV Abstract \#1390.

Zimbelman, J. R., 2010, Geologic Mapping of the MC-23 NW Quadrangle: Emplacement and Erosion of the Lower Member of the Medusae Fossae Formation on Mars. Lunar and Planetary Science XXXXI Abstract \#1157.

\section{Acknowledgments}

This work was funded by a UK Science and Technology Facilities Council

(STFC) studentship and through the STFC Aurora Fellowship scheme. The authors would like to thank Dr. Jim Zimbelman and an anonymous reviewer for their invaluable comments and suggestions that greatly improved the manuscript. 


\section{$1 \quad$ Figure captions}

3 Figure 1: Global DEM (128ppd) demonstrating the spatial context and extent of the

4 Medusae Fossae Formation (MFF). The black polygons in the local subset represent the

5 rough boundaries of the individual lobes of the formation. The crustal dichotomy

6 boundary and the MFF's adjacent position can be clearly seen. Image credit:

7 NASA/MSSS/USGS.

9 Figure 2: Examples morphology from each of the five lobes of the MFF. a - Lobe A in

10 MOC NA image M07/02180 $\left(214.38^{\circ}, 1.46^{\circ}\right), b$ - Lobe B in MOC NA image E16/02285

$11\left(207.71^{\circ}, 1.98^{\circ}, \mathrm{c}-\right.$ Lobe C in MOC NA image M07/02913 $\left(176.09^{\circ},-5.95^{\circ}\right), \mathrm{d}-$ Lobe D

12 in MOC NA image M03/01027 (159.49 $\left.{ }^{\circ}, 7.34^{\circ}\right)$, e - Lobe E in MOC NA image

$13 \mathrm{E} 04 / 02109\left(145.45^{\circ},-4.15^{\circ}\right)$. These represent just a small subset of the range of

14 morphologies seen across the formation. Image credit: NASA/JPL/MSSS.

16 Figure 3: Spatial context of the transect lines used in the initial survey. A - Transects 1

17 and 2 through lobes $\mathrm{A}$ and $\mathrm{B}, \mathrm{b}$ - Transect lines 3, 4 and 5 through lobes $\mathrm{C}, \mathrm{D}$ and $\mathrm{E}$.

18 Image credit: NASA/MSSS/USGS.

20 Figure 4: Spatial context of the Mangala Valles region in relation to the Medusae Fossae

21 Formation eastern lobes (D and E) and transect lines 4 and 5. The polygonal area 
22 represents the area used for the local survey of images. Image credit:

\section{NASA/MSSS/USGS.}

25 Figure 5: MOC NA and CTX coverage for the survey area within the polygon. It can be

26 seen that the spacing of the coverage for the area is quite discontinuous (up to $400 \mathrm{~m}$ for

27 CTX, up to $500 \mathrm{~m}$ for MOC NA). Note also the areas of continuous local areal coverage

28 for CTX. Image credit: NASA/MSSS/USGS.

30 Figure 6: Example of the discontinuous and degraded Medusae Fossae outlier materials

31 found in the Mangala Valles region (MOC NA image E16/02118 153.50, 4.42). Note

32 how the materials trend SE-NW. Image credit: NASA/JPL/MSSS.

34 Figure 7: Example of the Medusae Fossae outlier materials that occur over two

35 underlying and flattened craters (MOC NA image R10/01181 $211.83^{\circ},-15.01^{\circ}$ ). Note

36 how in some outliers, the materials are less degraded on the raised edges and follow the

37 dominant SE-NW orientation. Image credit: NASA/JPL/MSSS.

39 Figure 8: Example of bidirectionality of the yardang ridges in the outlier materials,

40 wherein degradation has resulted in a crosshatch appearance (M07/00807 156.41 $\left.{ }^{\circ},-10.8\right)$.

41 The two directional trends in this case are SE-NW and SW-NE. Image credit:

42 NASA/JPL/MSSS. 
44 Figure 9: Comparison of degraded upper member materials on lobe D (a - MOC NA

45 image E11/01999 $\left.156.61^{\circ} .-7.58^{\circ}\right)$ with an example of the outlier materials $(\mathrm{b}-\mathrm{MOC}$

46 NA image R11/04489 $148.34^{\circ},-6.43^{\circ}$ ). Both show a rough SE-NW directional trend in

47 the yardang ridge features and preferentially occur in topographic lows. Image credits:

$48 \quad$ NASA/ /MSSS.

51 Figure 10: Map showing the recorded occurrences of MFF outlier materials and the

52 spatial extents of these examples. The largest continuous extent can be seen in the north

53 of the study area and extending to the north of it, between lobes D and E of the main

54 formation, with other the main occurrences clustered in the north west of the area.

55 Towards the south of the study area, the extents become considerably smaller and more

56 widely spaced. Image credit: NASA/MSSS/USGS.

57 Figure 11: Close-up of a portion of Fig. 10, which gives closer look at a section of the

58 study area in which the outlier spatial extents are much smaller, and in fact largely

59 typified by traces occurrences. The exception to this trend is the relatively large extent

60 which extends across the range of hills in the east of the image. Image credit:

61 NASA/MSSS/USGS.

64 Figure 12: A example of yardang morphology used to infer paleo-wind direction in a 65 section of HiRISE image PSP_007973_1750 $\left(209.6^{\circ}-4.9^{\circ}\right)$ showing a yardang in the 66 MFF material. Note the inverted "ships hull" shape. In yardang morphology, the blunt 
67 nose is the windward face, whilst the tapered tail is the leeward face and so the dominant

68 wind direction in this case can be inferred as SE-NW. Typically the blunt windward face

69 may also be undercut although this is not obvious in this image. Image credit:

70 NASA/JPL/University of Arizona.

73 Figure 13: Map showing the dominant orientation/wind direction trends are inferred from

74 examination of yardang morphology in selected HiRISE images. Comparative

75 orientations are also given for areas of lobes D and E. The most commonly occurring

76 wind direction is SE-NW, with also a number of instances of NW-SE. In a few cases, a

77 completely different orientation can be seen in the materials - either SW-NE or NE-SW -

78 and in others, the crosshatching as seen in Fig. 8, occurs. Image credit:

79 NASA/MSSS/USGS.

80 Figure 14: Chart showing the derived elevation statistics for the differing Medusae

81 Fossae Formation exposures, including each main lobe, the different members within

82 these lobes and the outliers observed in the Mangala Valles region. The hollow circles

83 represent the mean elevations, whilst the extent bars describe the minimum and

84 maximum elevation ranges. The outlier elevation trends are most similar to those of the

85 upper member and Lobe E (typified by the upper member).

88 Figure 15: Map showing the potential paleo extent of the Medusae Fossae Formation,

89 encompassing Lobes D, E and the outliers. This was inferred from the outlier extents as 
90 shown in Fig. 10 and assumes a continuous layer of deposit across the area. This extent

91 was used as the basis for paleovolume calculations. Image credit: NASA/MSSS/USGS

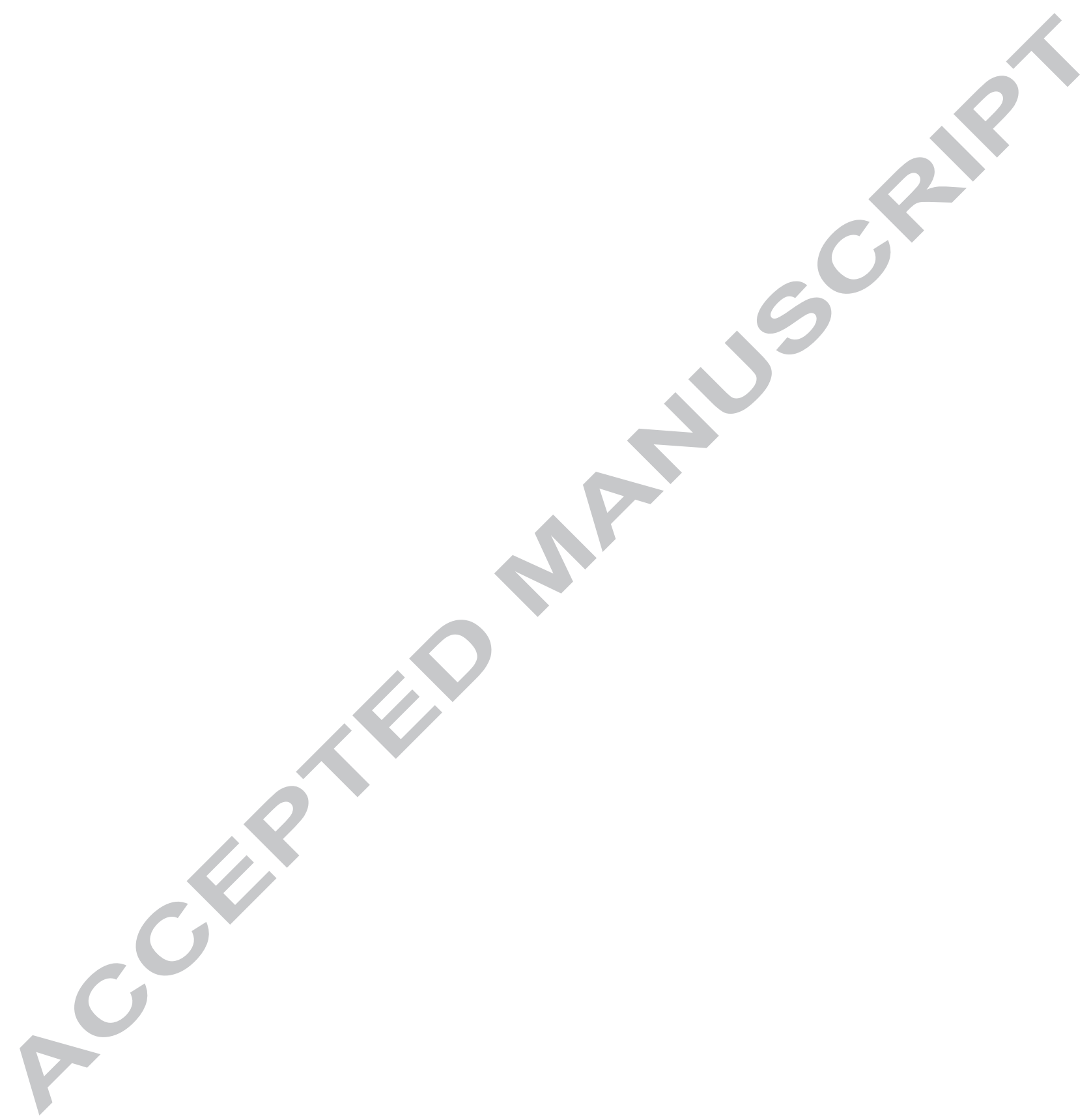



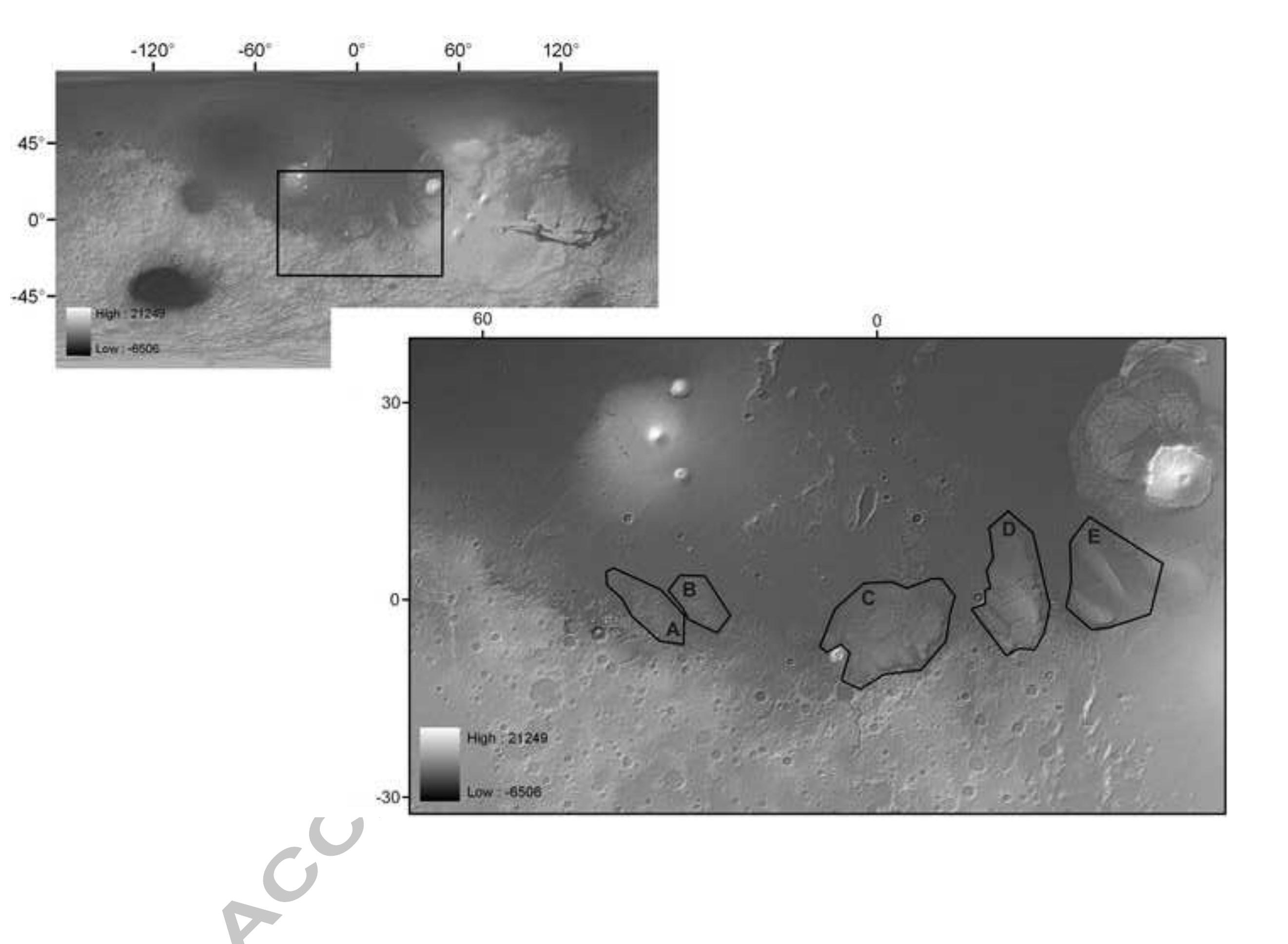

$\begin{array}{lll}0^{\circ} & 60^{\circ} & 120^{\circ}\end{array}$
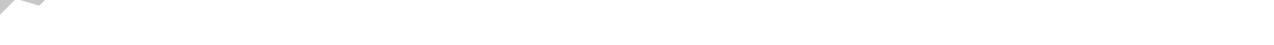

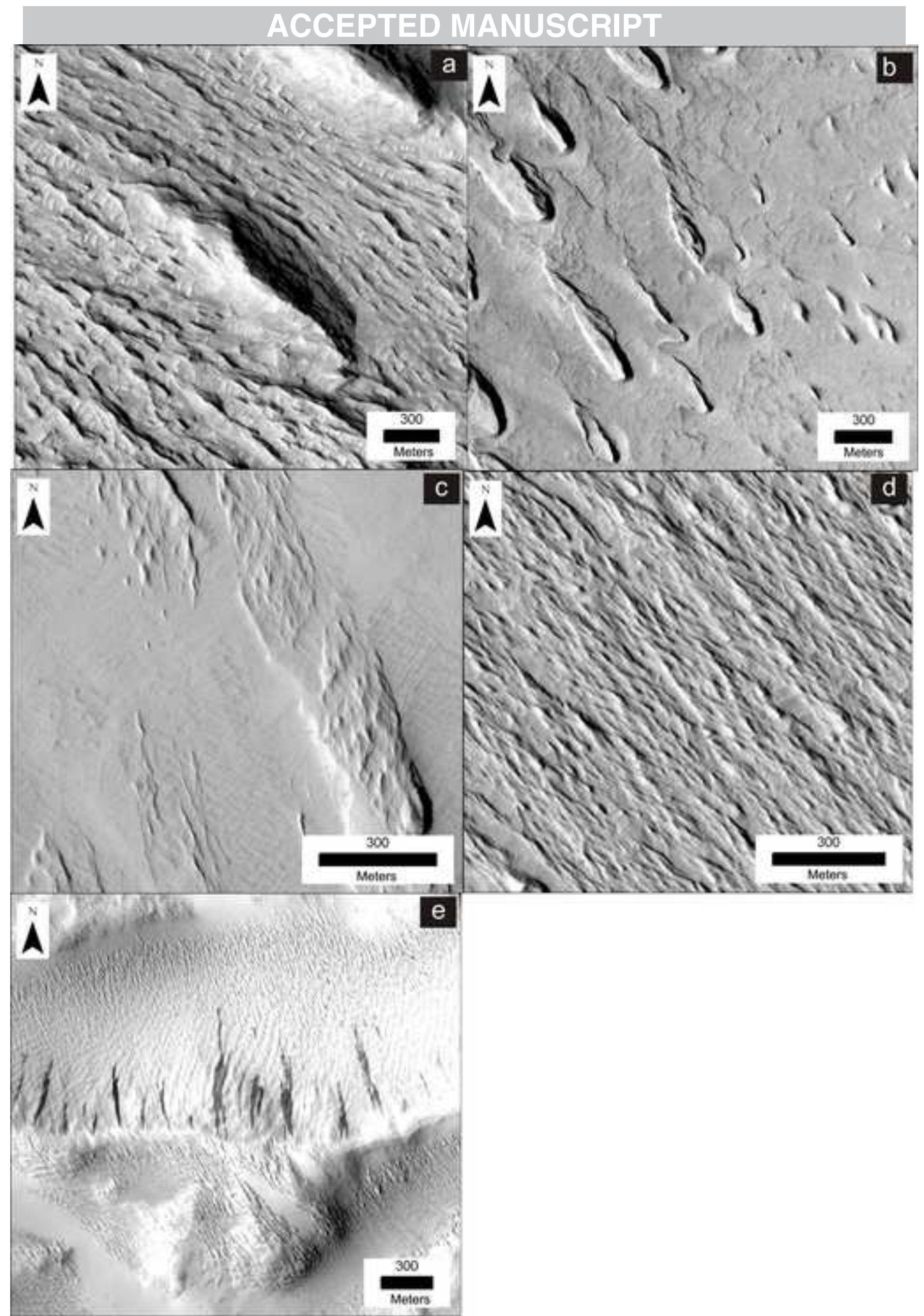
Fig 3a

\section{ACCEPTED MANUSCRIPT}

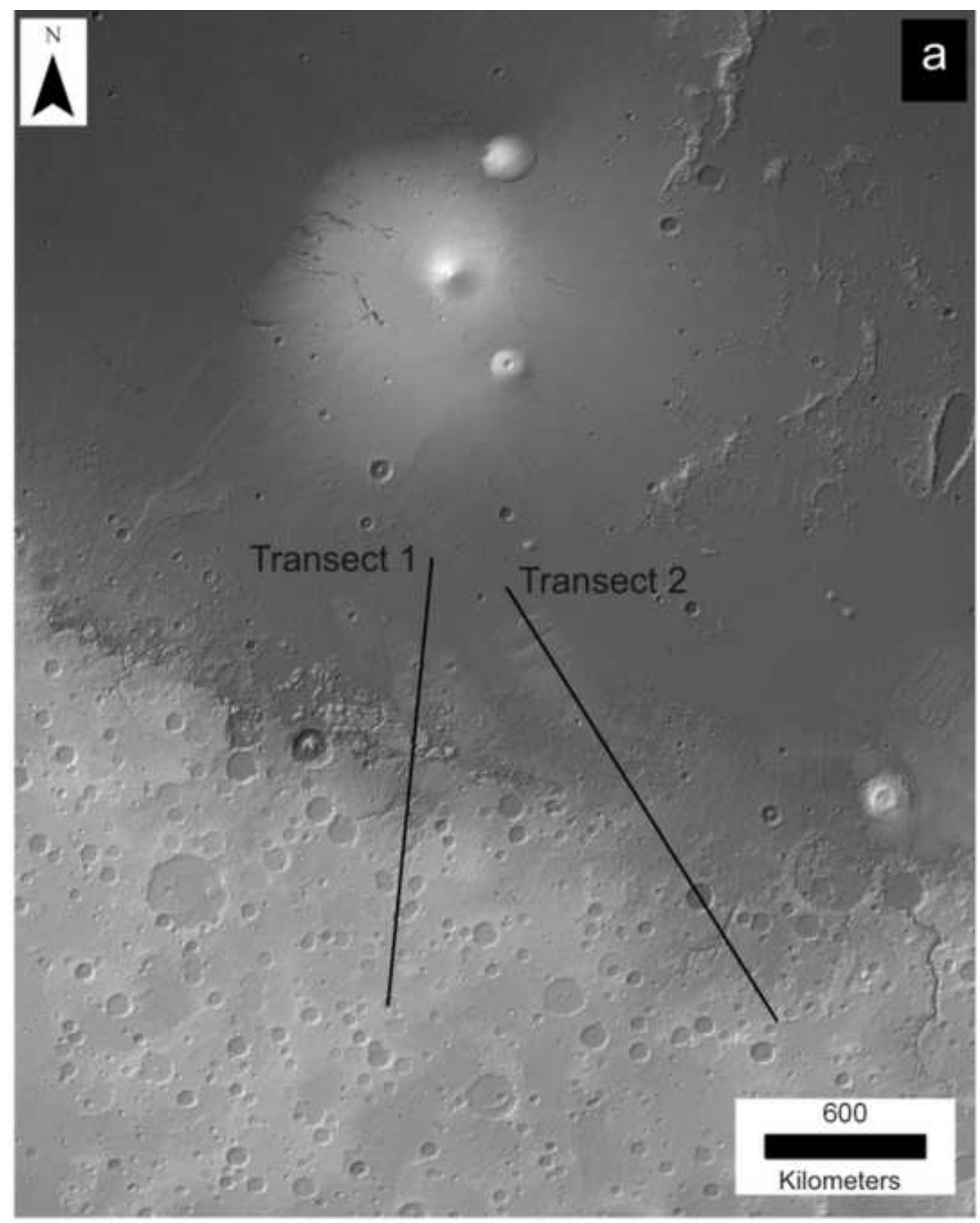

Transect lines

600

Kilometers

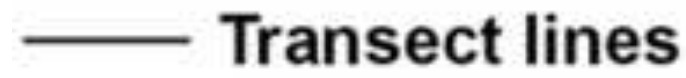

\section{Transect lines}
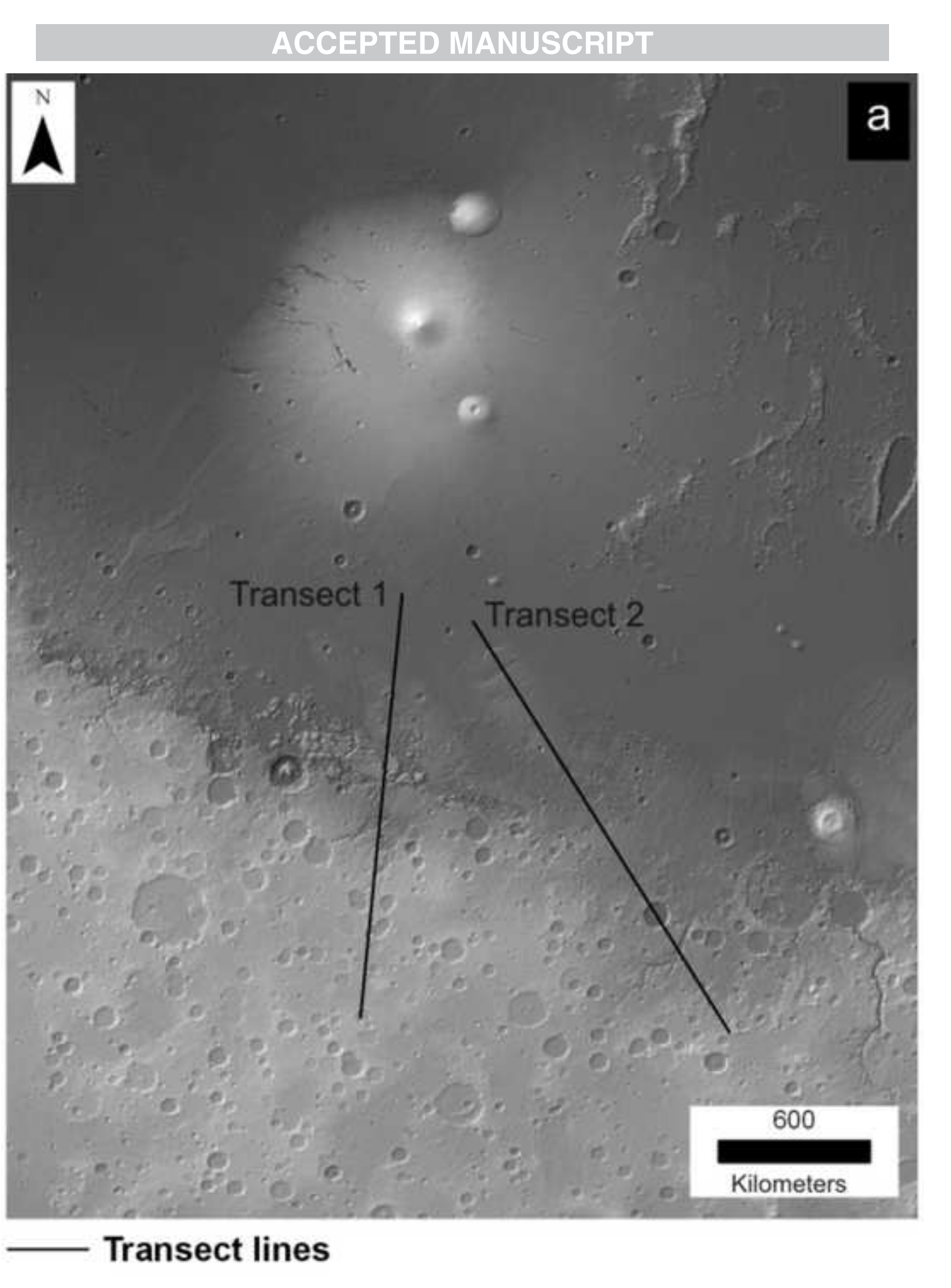

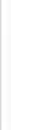 \\ .}

\section{.}

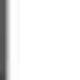


Fig $3 b$

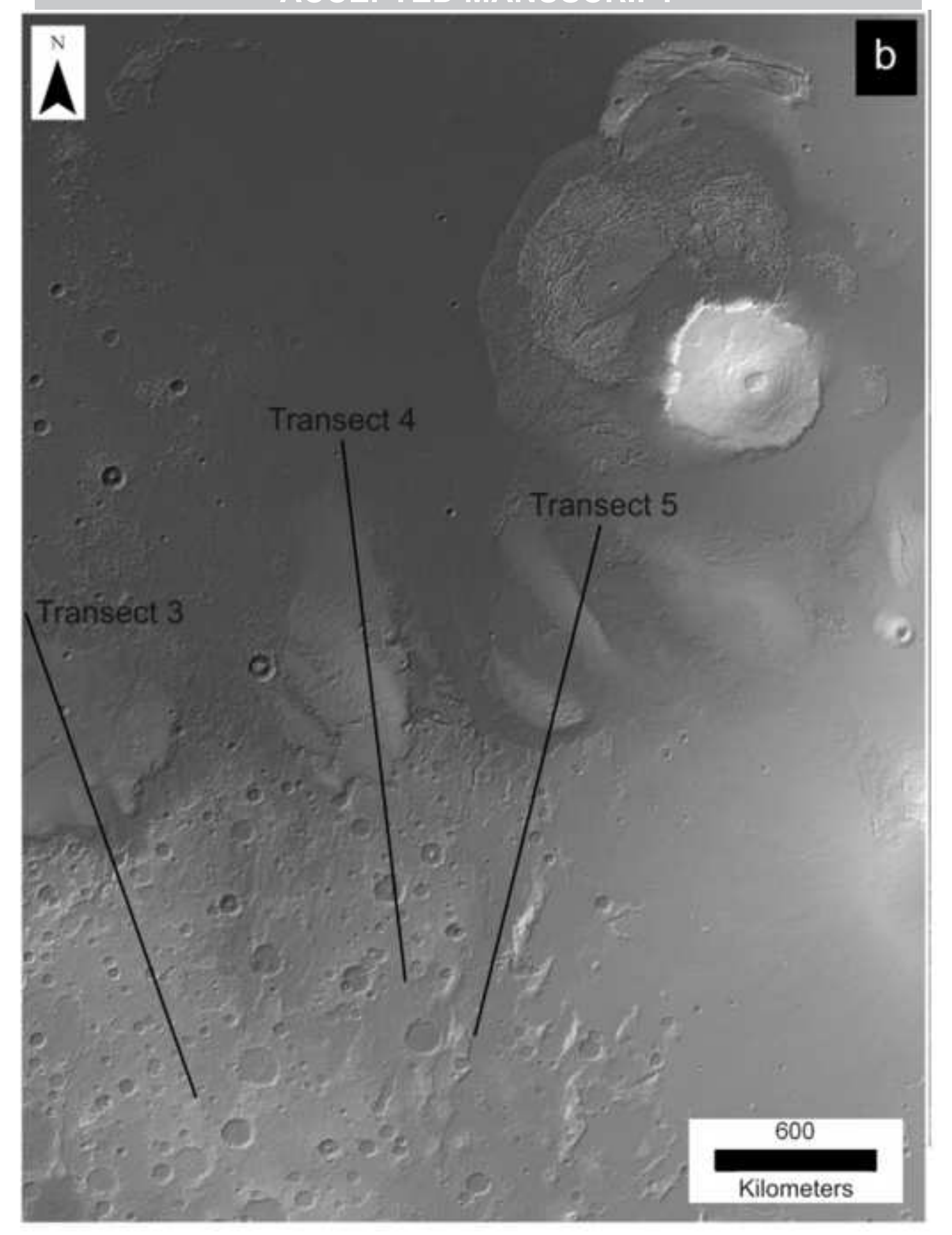

\section{ACCEPTED MANUSCRIPT}

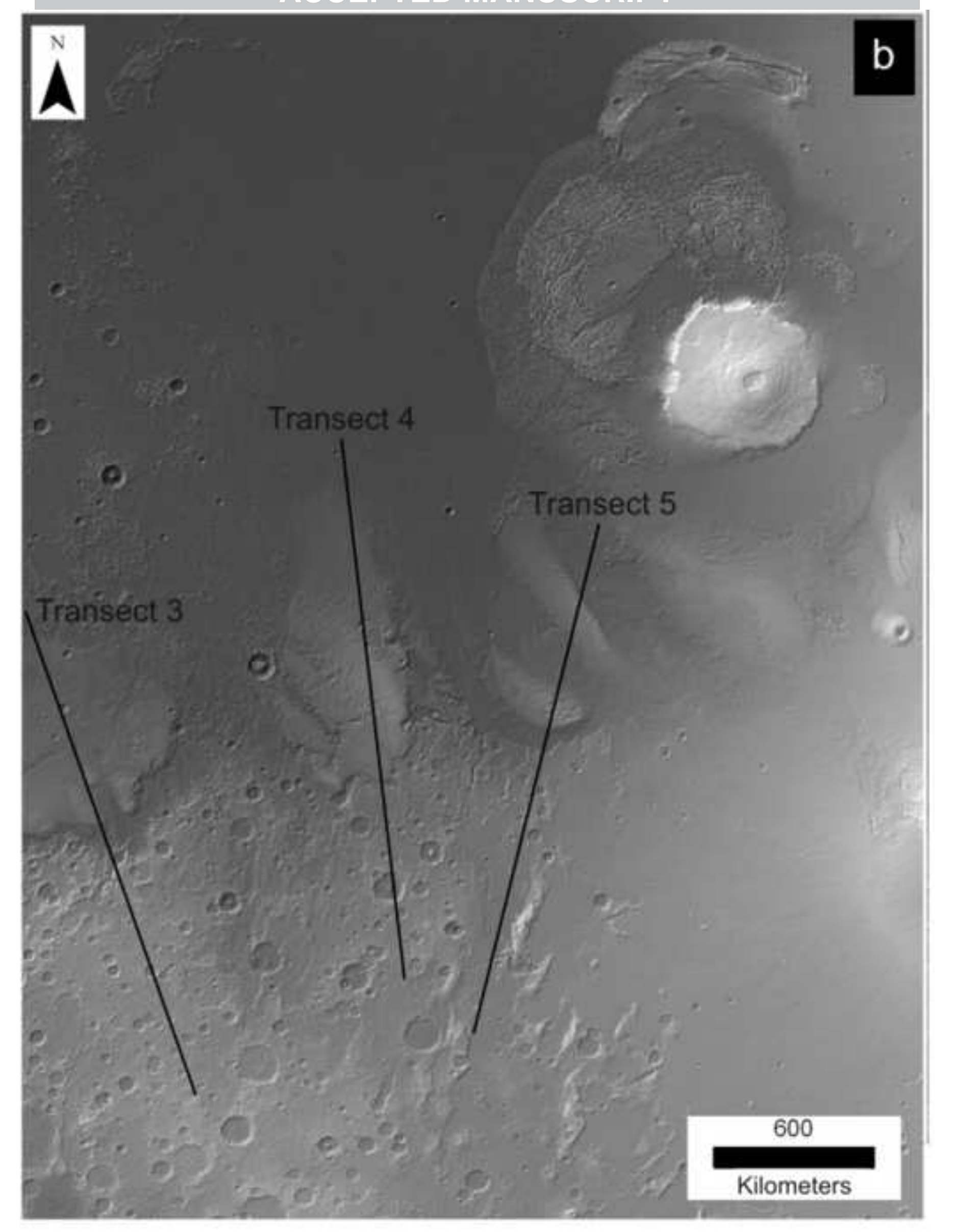

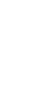

(

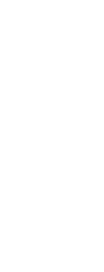


Fig 4

ACCEPTED MANUSCRIPT

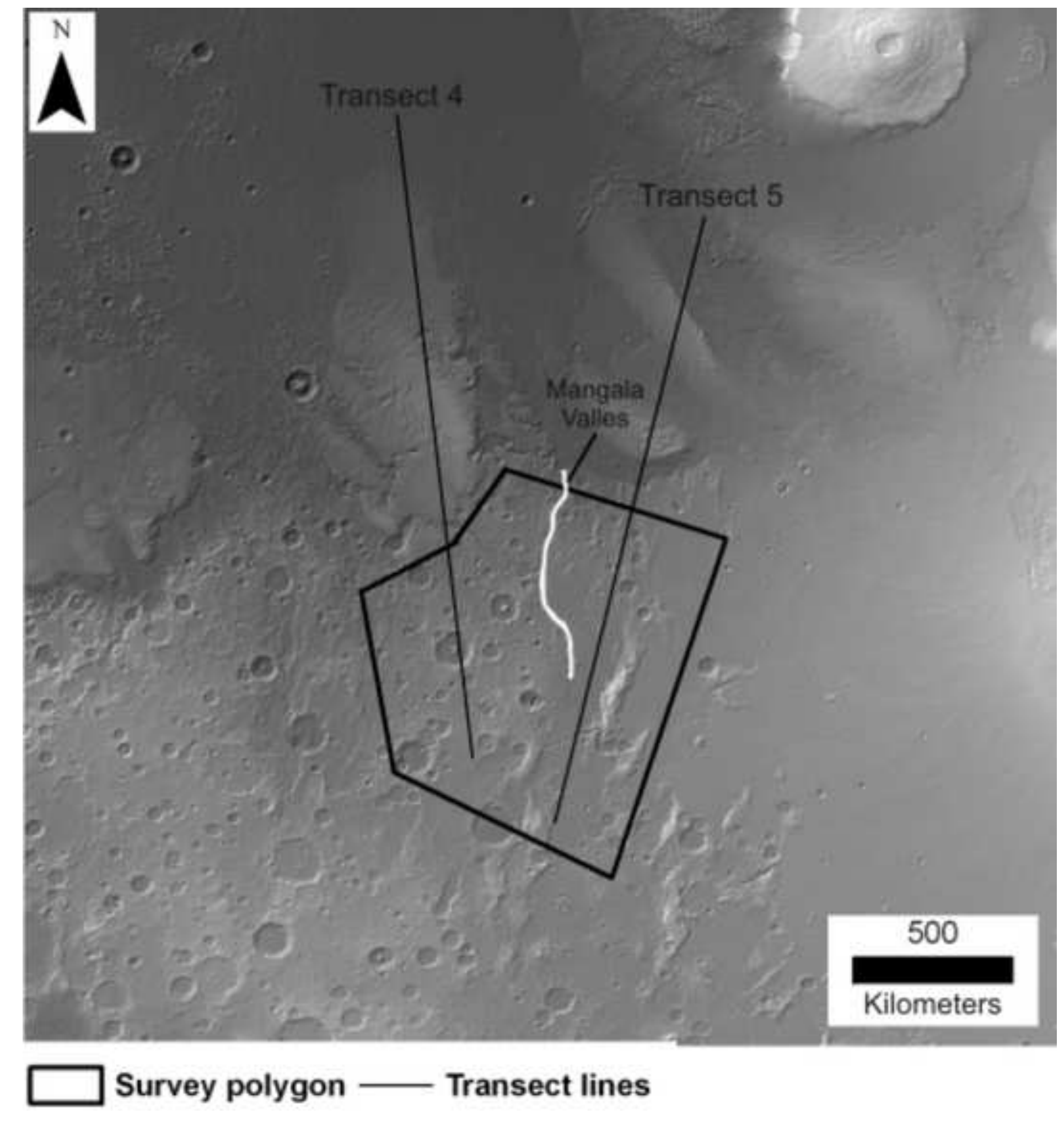

$\square$ Survey polygon — Transect lines

\section{Lurvey polygon}

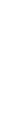

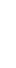

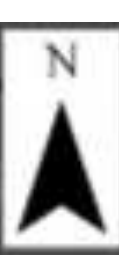
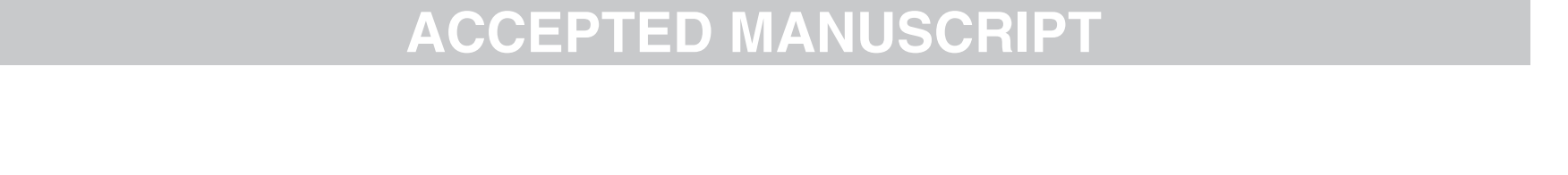

(a)

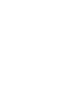
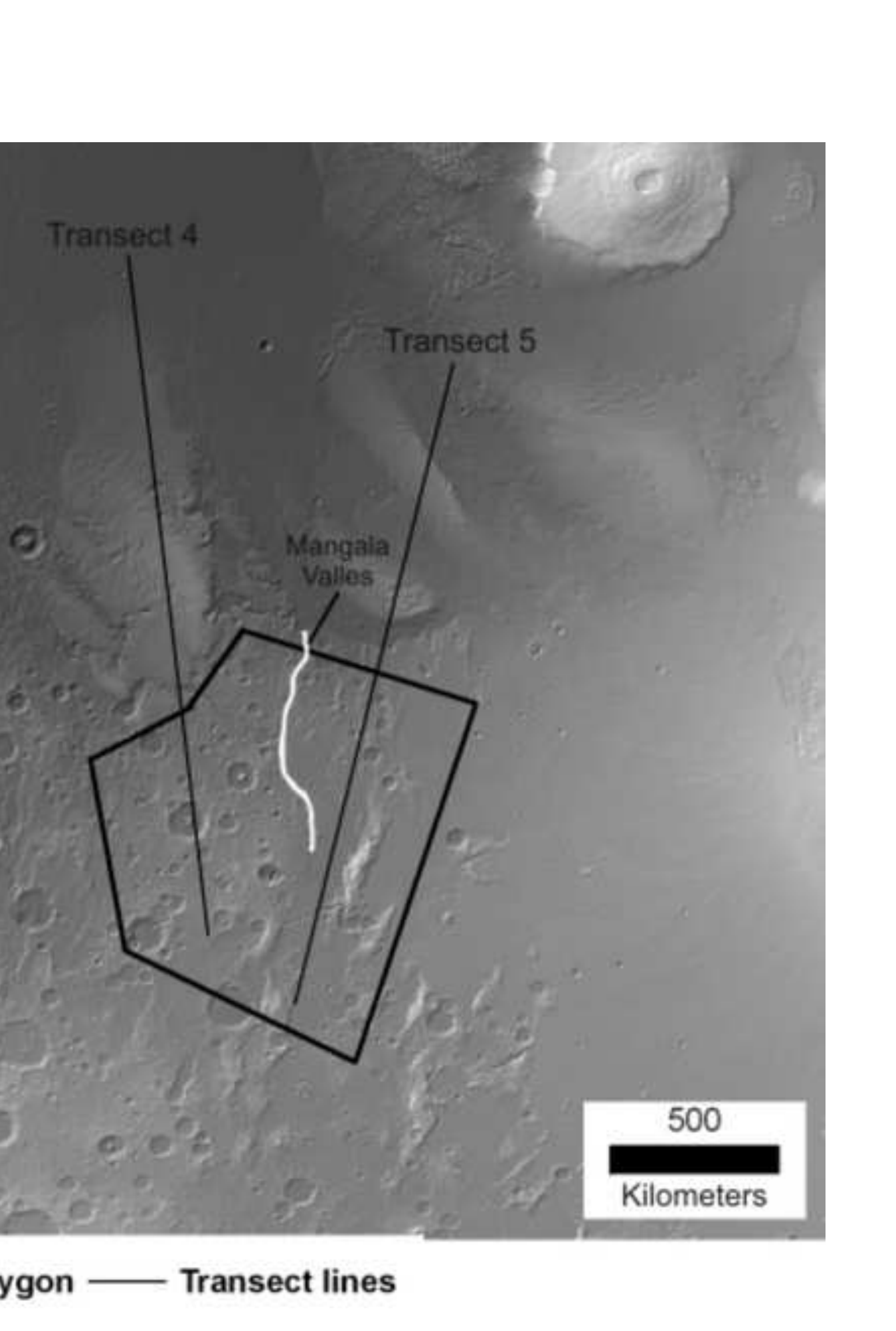


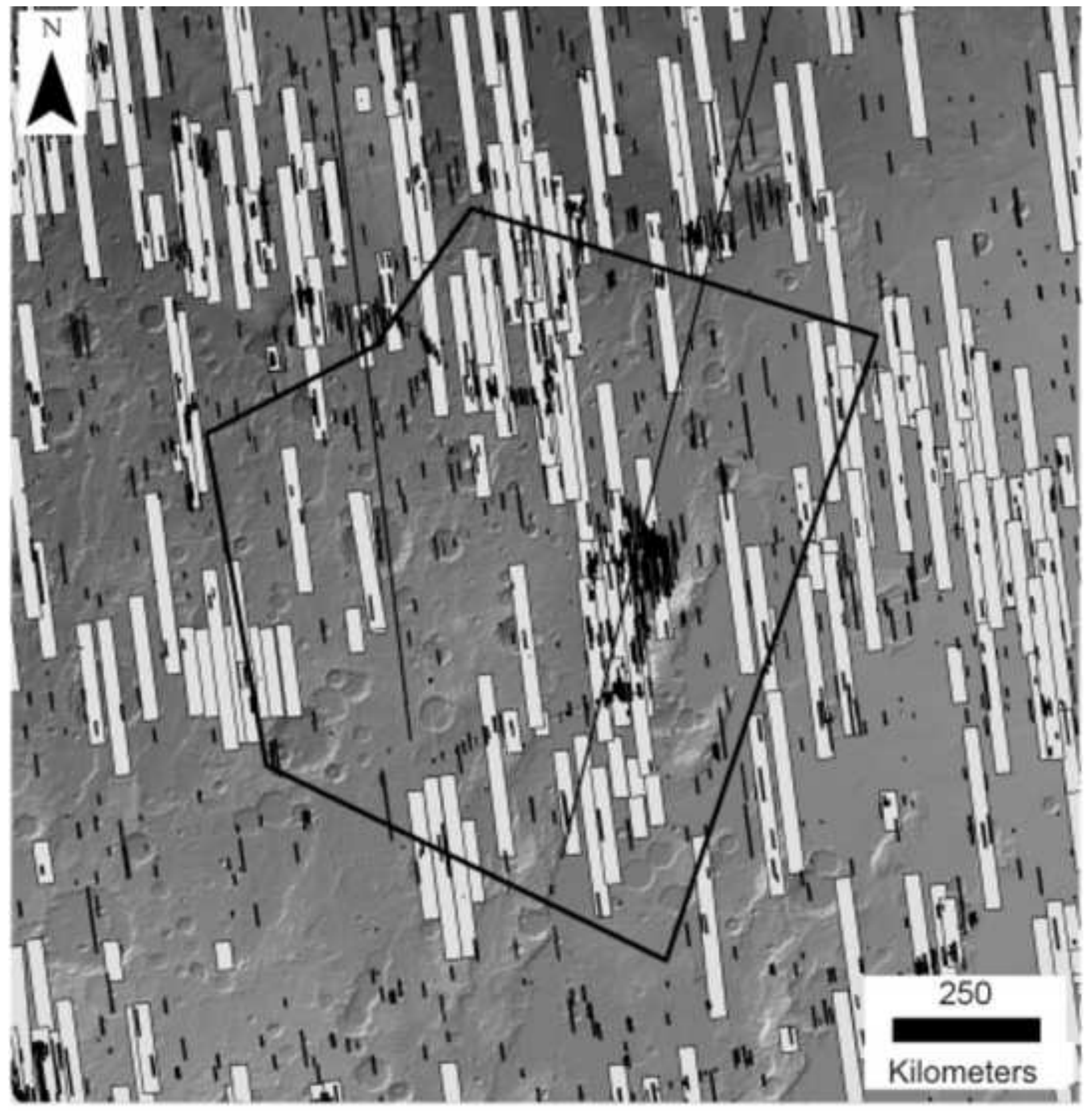



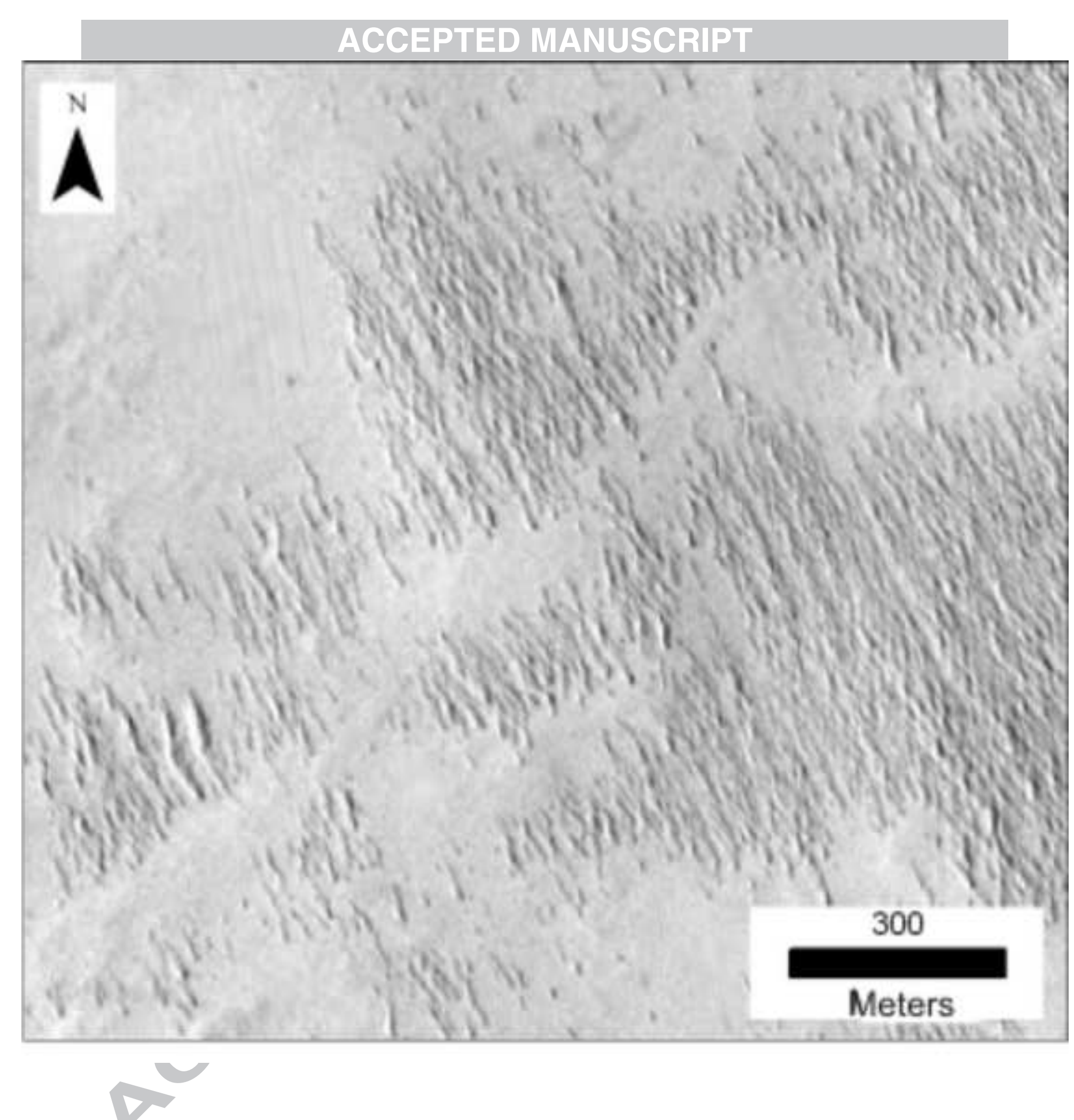

Meters 


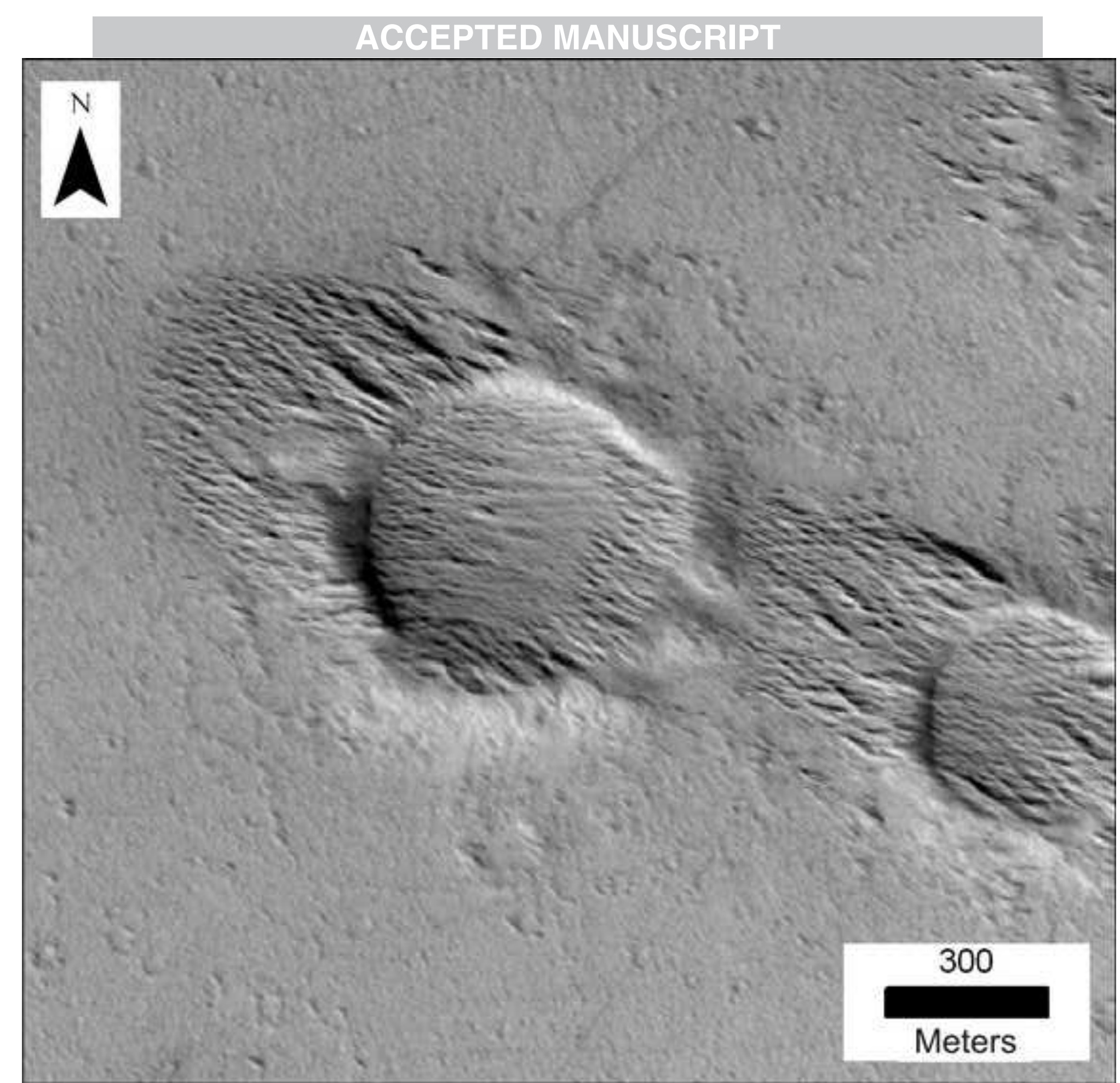

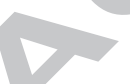

\section{Meters}




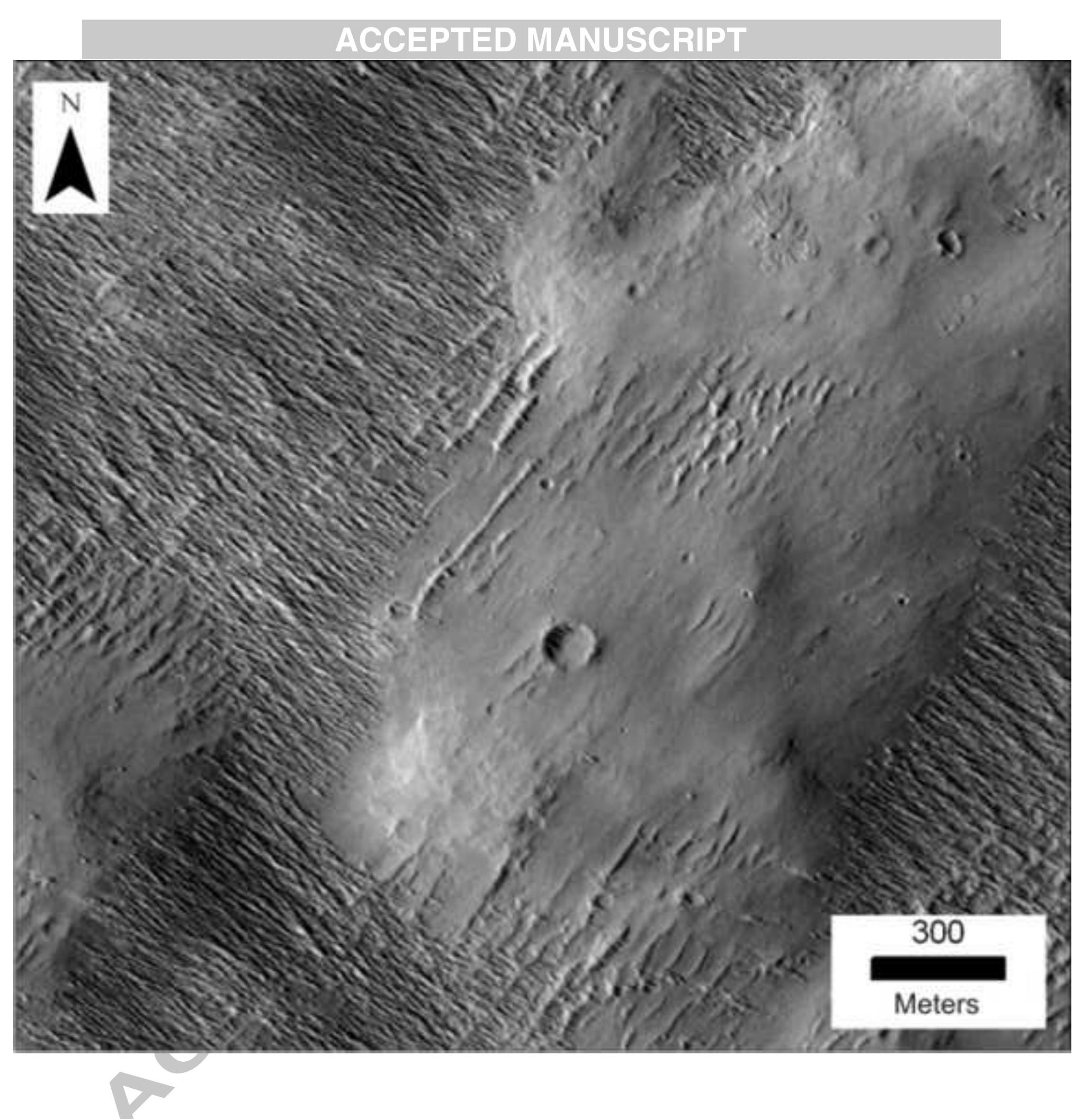

\section{N}

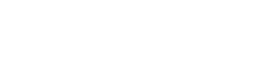




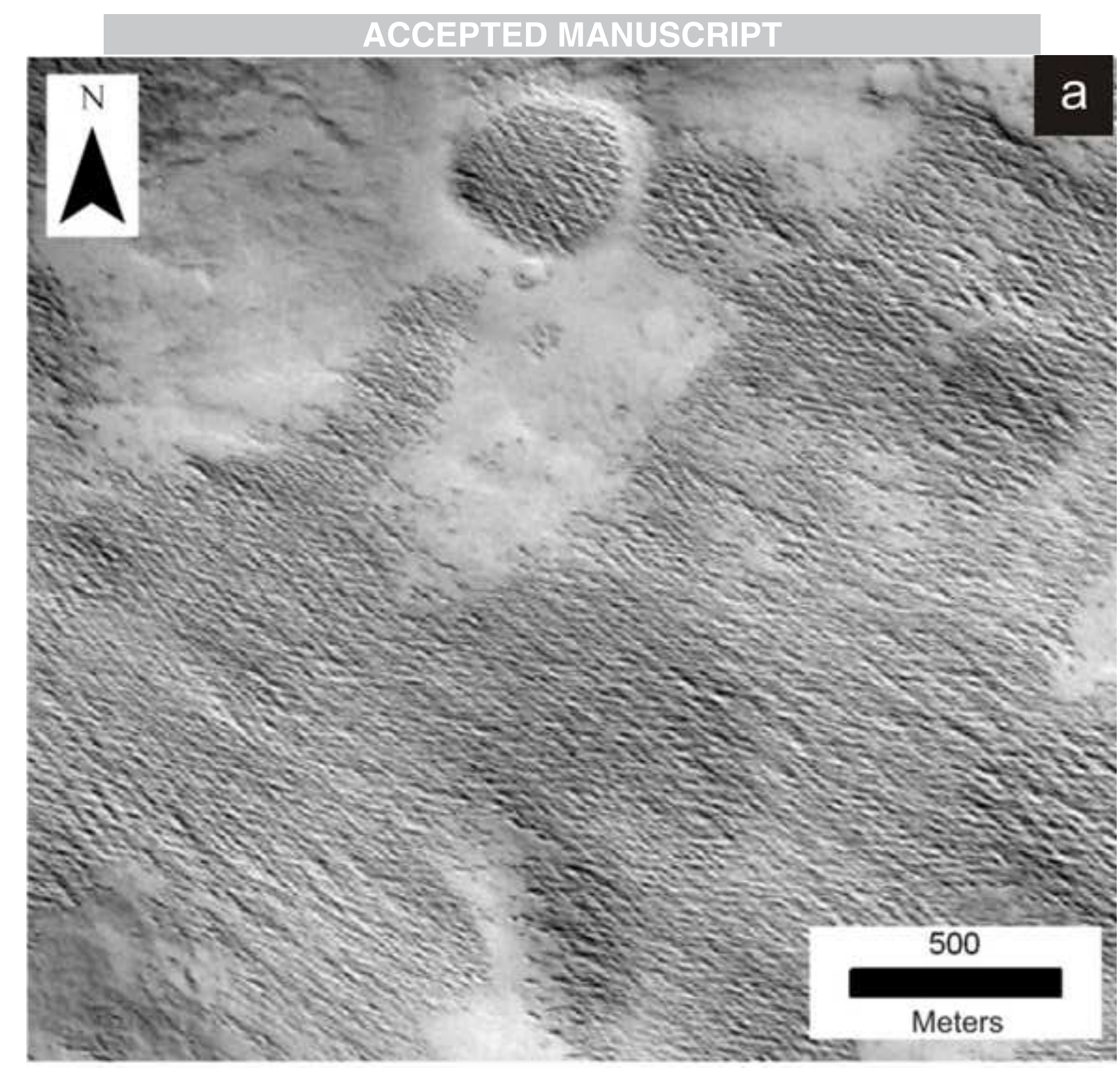

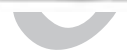

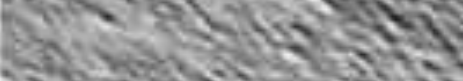

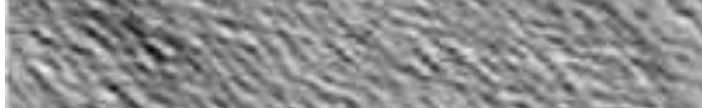

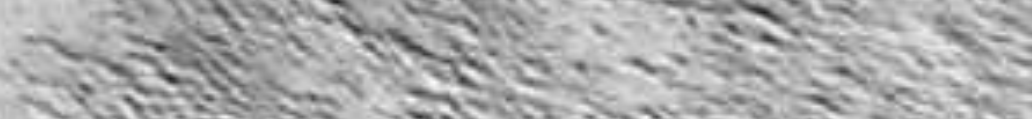

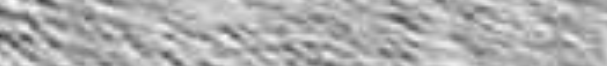

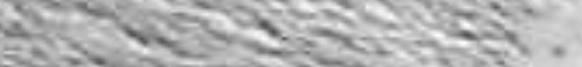
( (

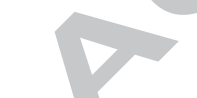

(

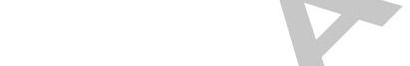



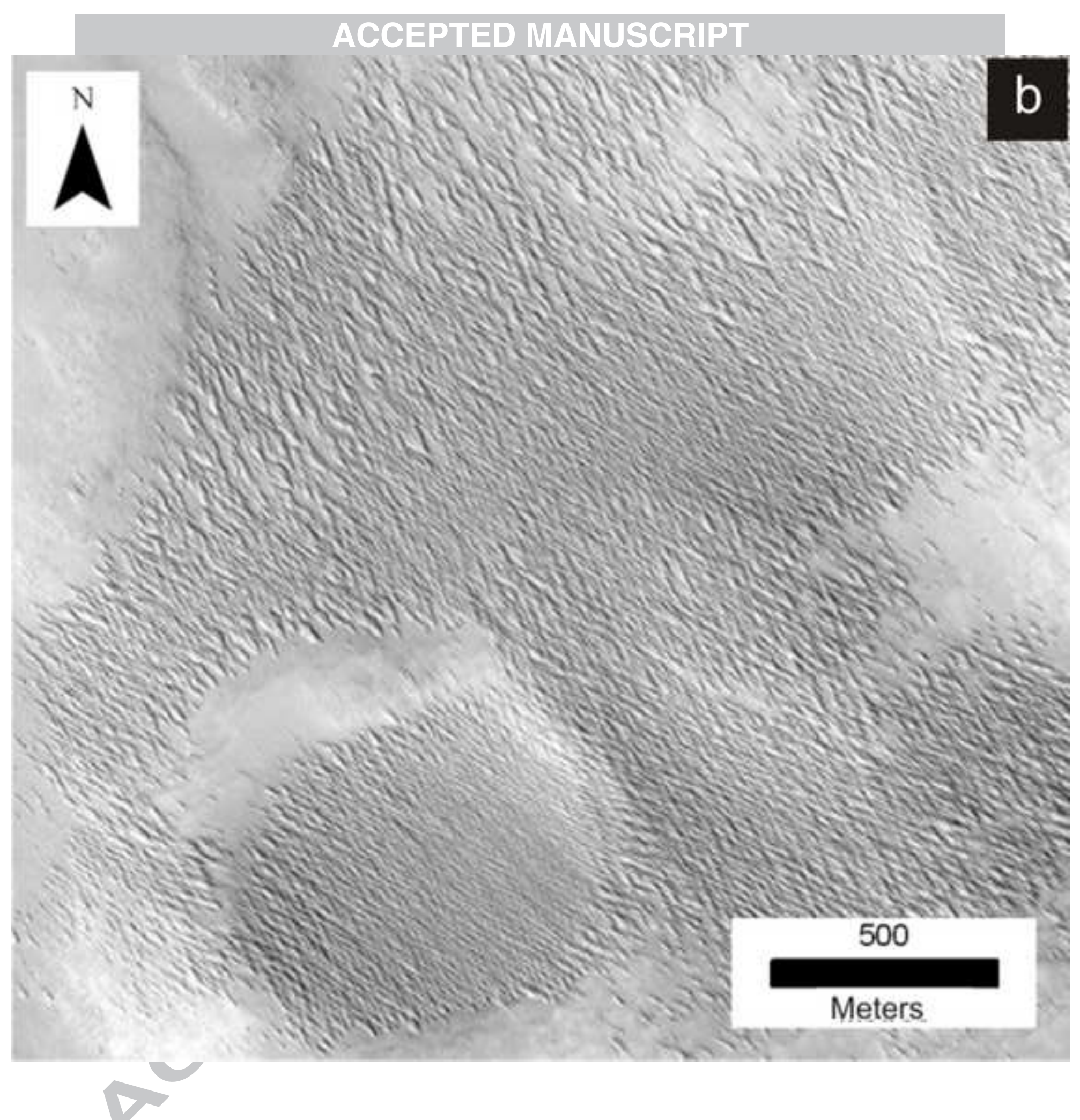


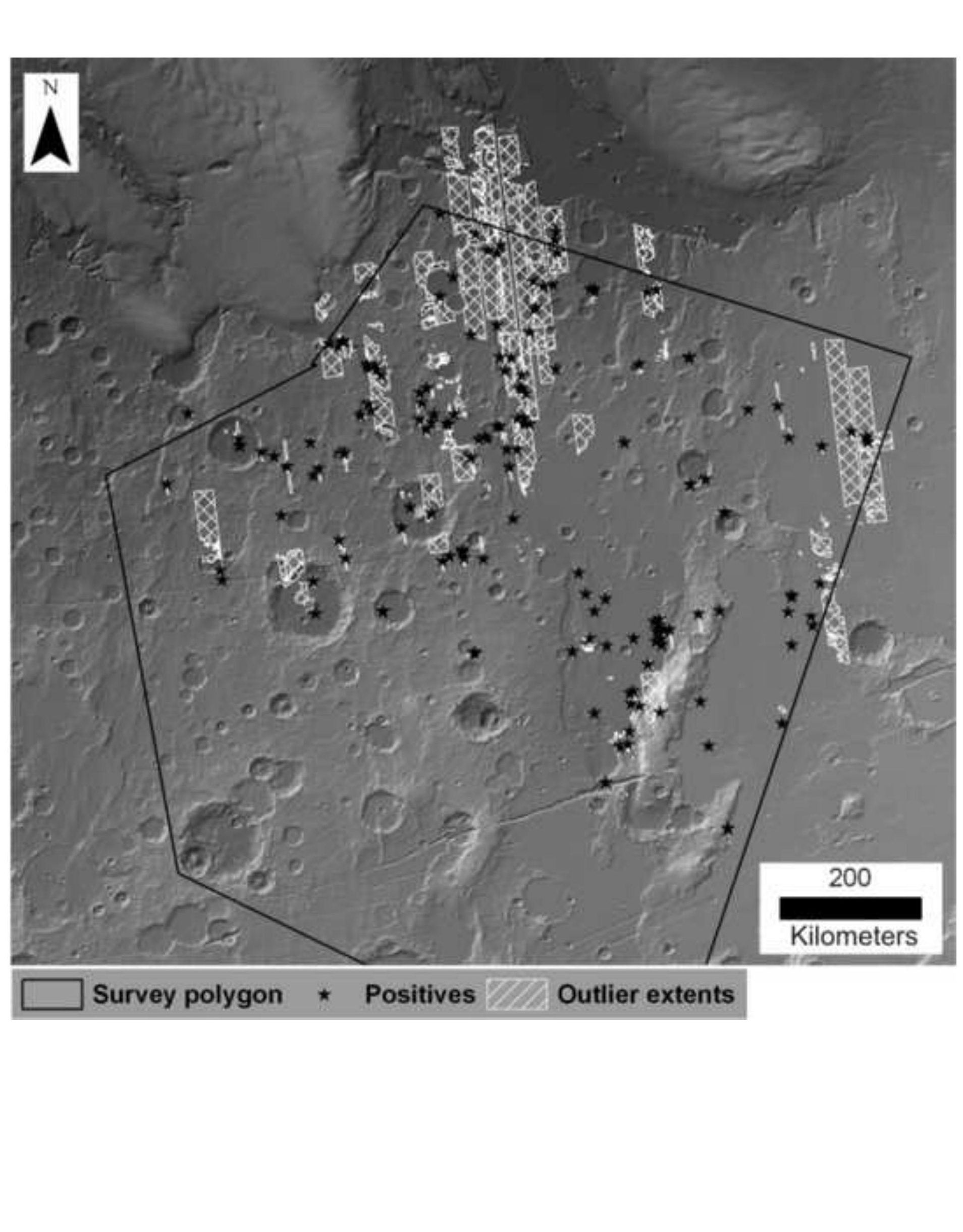

Fig 10

\section{$\square$ Survey polygon * Positives WIN Outlier extents}

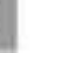




\section{ACCEPTED MANUSCRIPT}

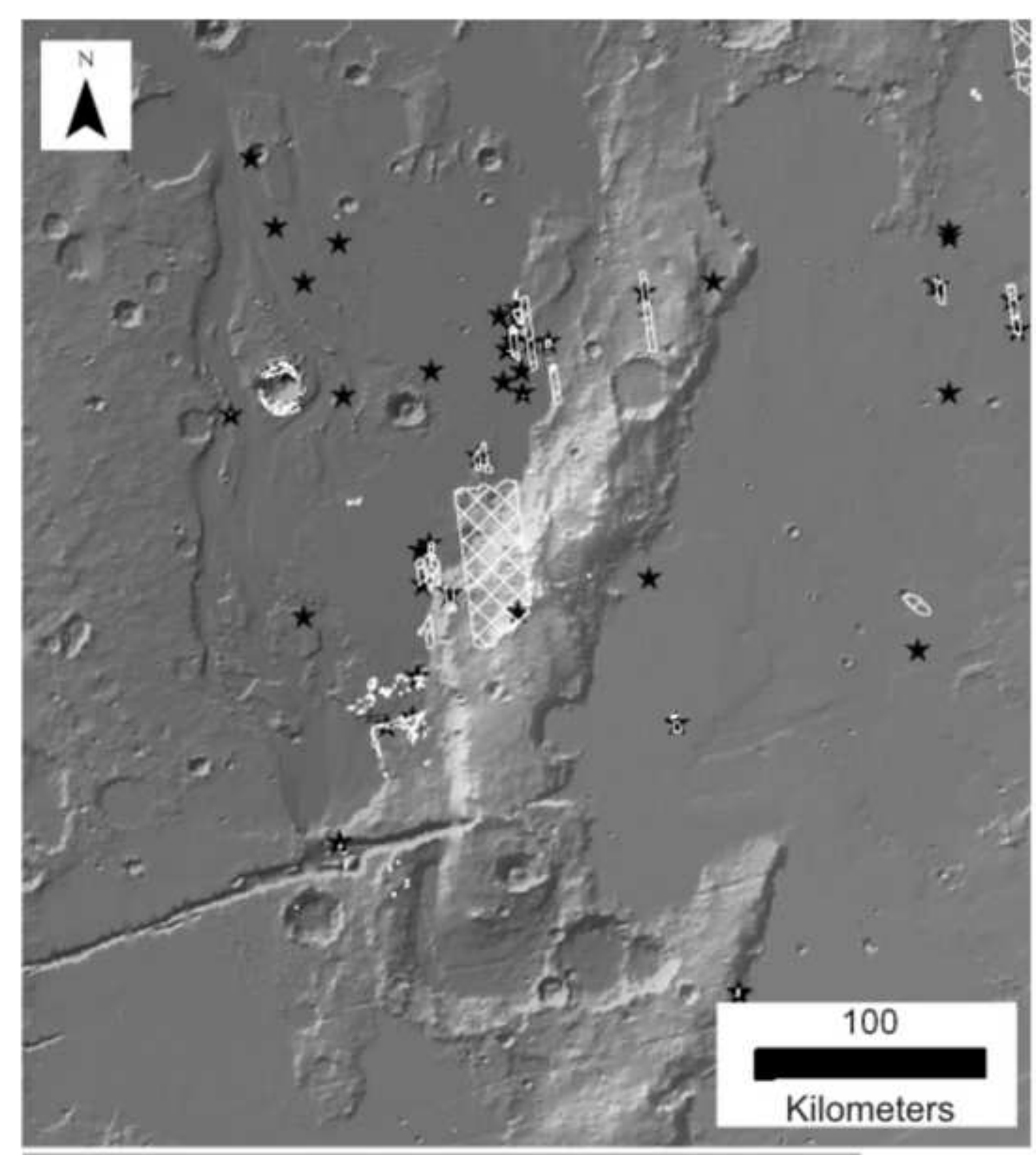

\section{* Positives DZ7\ Outlier extents}




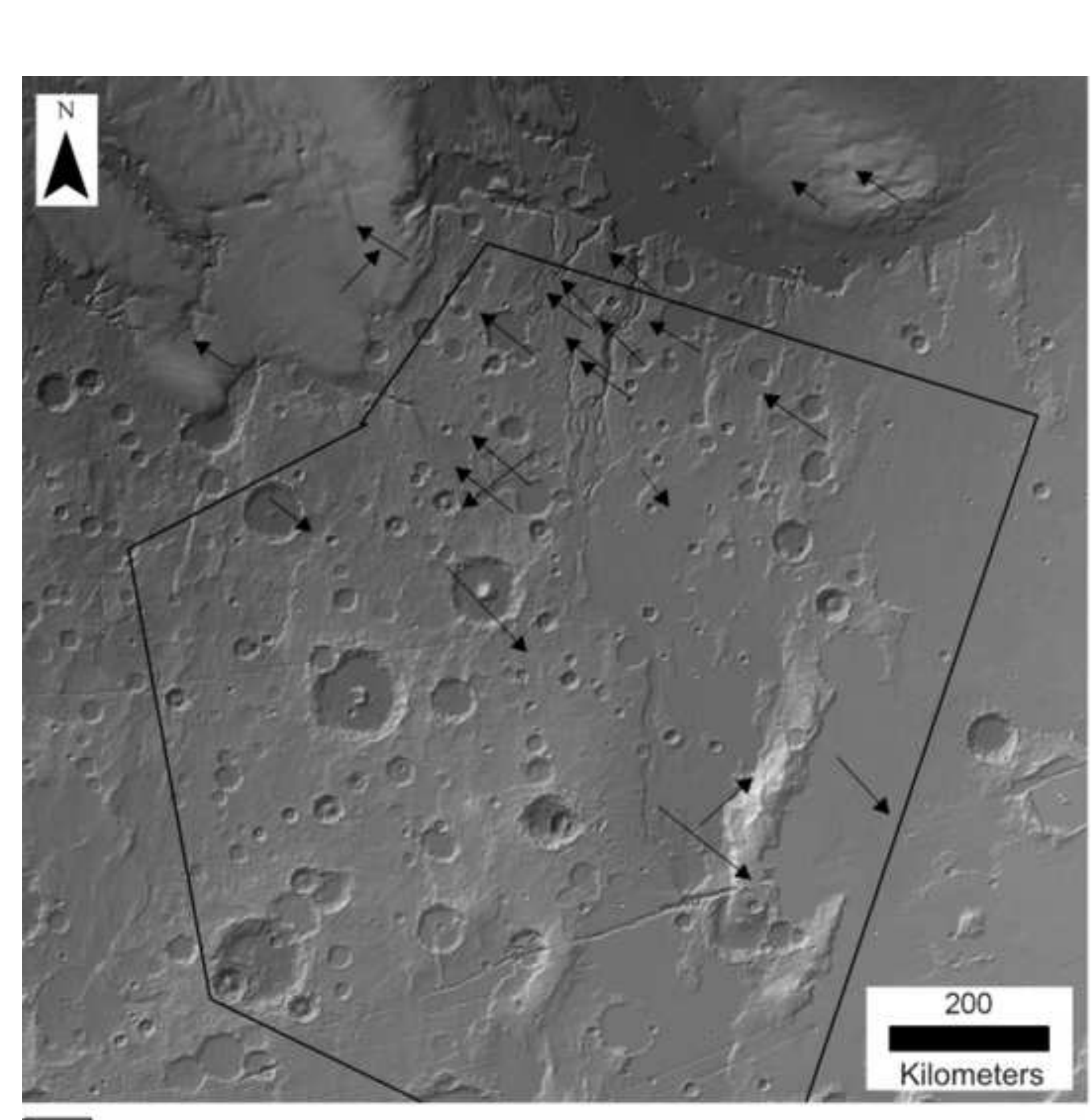

$\square$ Survey polygon $\longrightarrow$ Dominant orientation

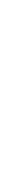

\section{( 15}
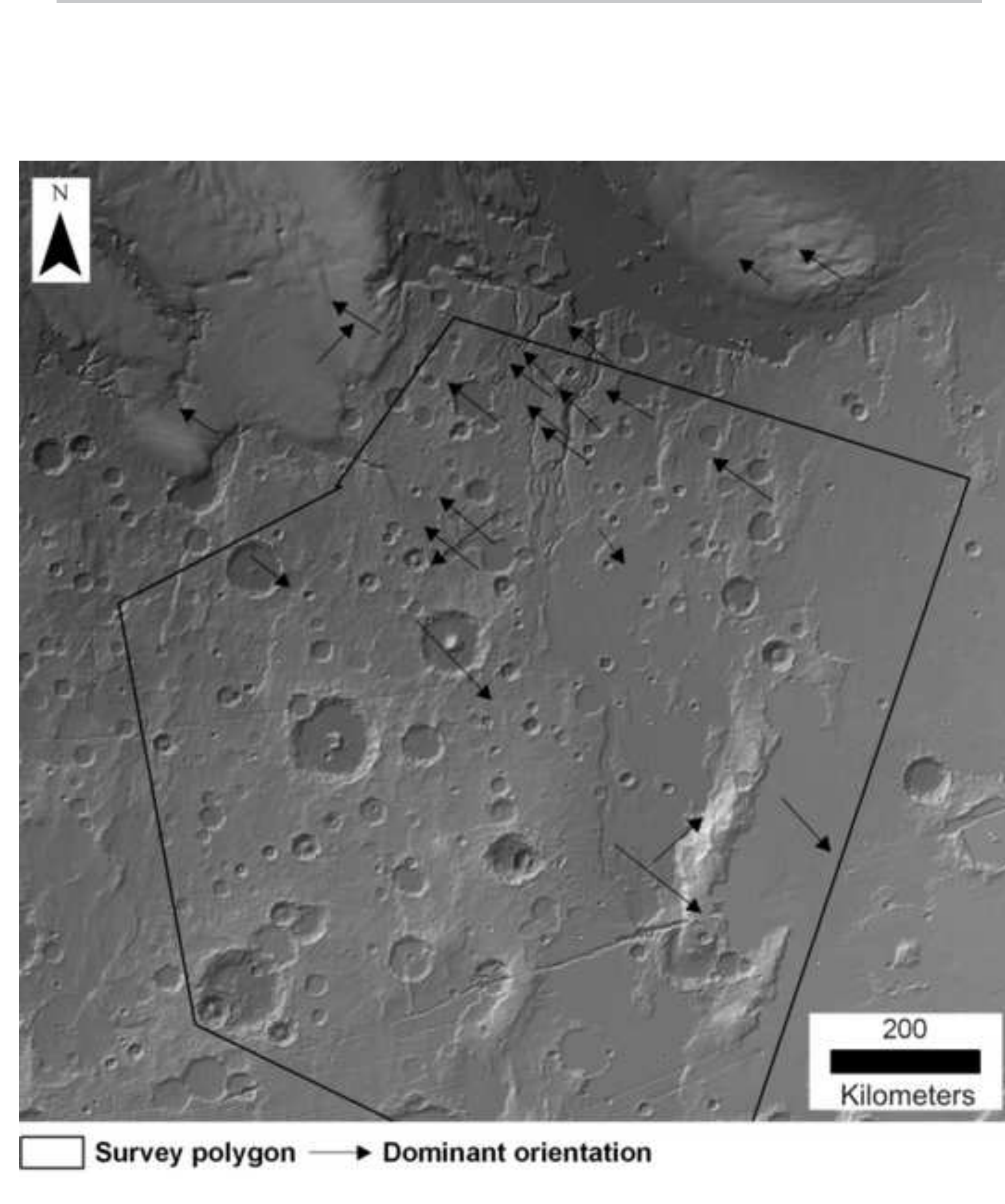

\section{.

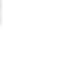




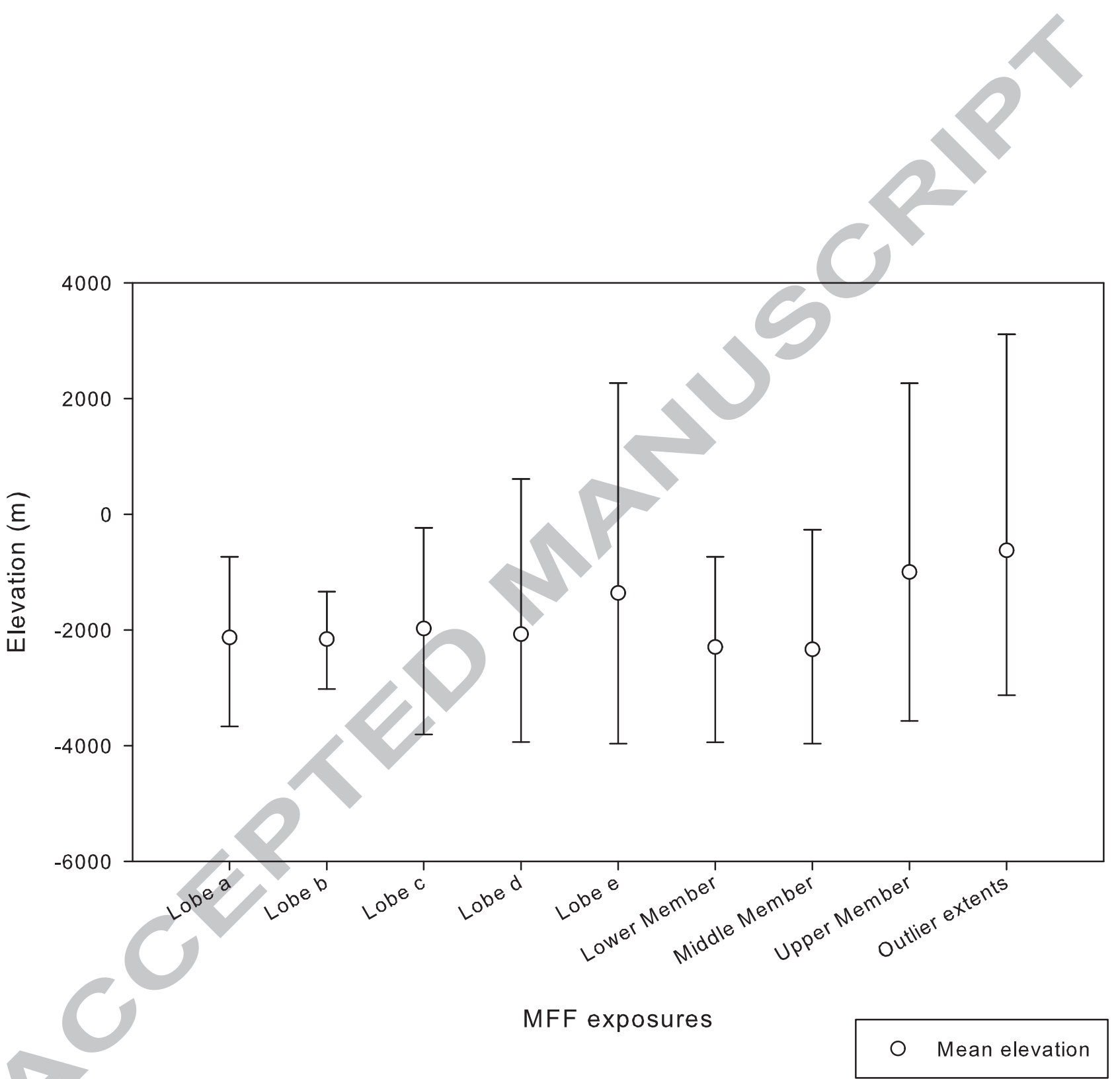



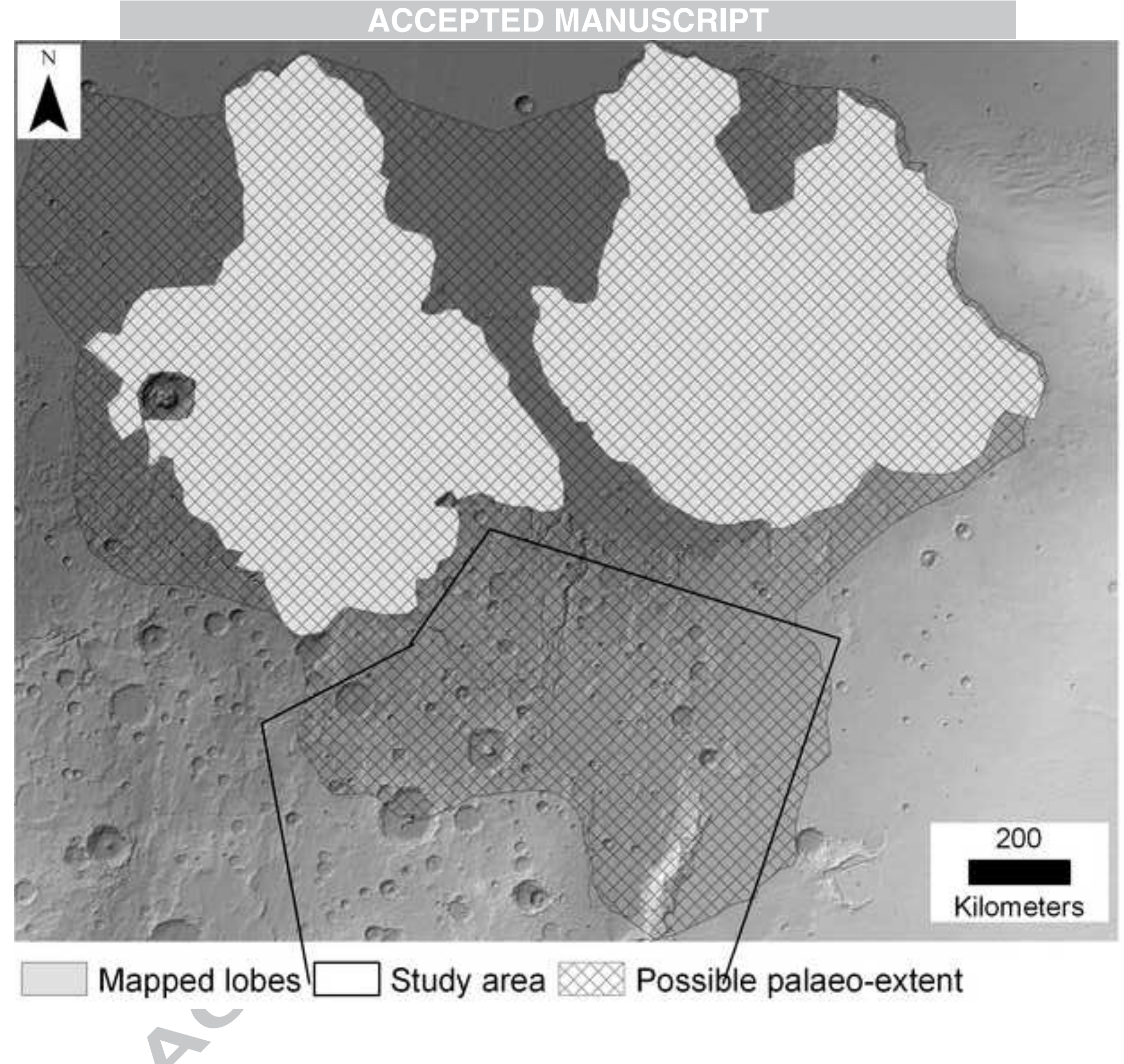
Tables

\begin{tabular}{|l|l|}
\hline Hypothesis & Source \\
\hline Ignimbrite/ash flow deposits & $\begin{array}{l}\text { (Zimbelman et al., 1996; Tanaka, 2000; } \\
\text { Zimbelman et al., 2003; Hynek et al., 2003; } \\
\text { Shockey et al., 2004; Mandt et al., 2007; } \\
\text { Kerber et al., 2008) }\end{array}$ \\
\hline Pyroclastic material & $\begin{array}{l}\text { (Zimbelman et al., 1997; Bradley et al., 2002; } \\
\text { Zimbelman et al., 2003; Hynek et al., 2003; } \\
\text { Mandt et al., 2007; Kerber et al., 2008) }\end{array}$ \\
\hline Aeolian deposits (indurated) & $\begin{array}{l}\text { (Zimbelman et al., 1997; Zimbelman et al., } \\
\text { 2003; Mandt et al., 2007) }\end{array}$ \\
\hline $\begin{array}{l}\text { Ancient polar layered deposits } \\
\text { (Head, 2001) }\end{array}$ \\
\hline $\begin{array}{l}\text { Ice-rich deposits laid down during } \\
\text { periods of high obliquity or outflow } \\
\text { channel formation }\end{array}$ & $\begin{array}{l}\text { (Head, 2001; Head and Kreslavsky, 2001; Head } \\
\text { and Kreslavsky, 2004) }\end{array}$ \\
\hline $\begin{array}{l}\text { Carbonate platforms } \\
\text { (Parker, 1991) }\end{array}$ \\
\hline
\end{tabular}

Table 1: A selection of the proposed origin hypotheses for the Medusae Fossae Formation. For more detail, please see Mandt et al. (2008b)

\begin{tabular}{|l|l|}
\hline Member & Surface characteristics \\
\hline Upper $(\mathrm{Amu})$ & $\begin{array}{l}\text { Discontinuous but widespread; smooth to rolling; ridges and } \\
\text { grooves in some localities; curved margins; overlies the } \\
\text { dichotomy boundary up to elevations of } \sim 0.5 \mathrm{~km}(\sim 3.5 \mathrm{~km} \text { above } \\
\text { surrounding plain) }\end{array}$ \\
\hline Middle $(\mathrm{Amm})$ & $\begin{array}{l}\text { Rougher and more eroded than Upper, cut by joints and } \\
\text { intersecting joints; appears heavily dissected and modified at all } \\
\text { scales; has sections of highly modified teardrop hills separated by } \\
\text { valleys }\end{array}$ \\
\hline Lower $(\mathrm{Aml})$ & Smooth to rough; highly eroded; darker in colour \\
\hline
\end{tabular}


Table 2: Summary of the surface characteristics of Medusae Fossae geological members (Head and Kreslavsky, 2001) 